\title{
O ENSINO DA MATEMÁTICA NA ENGENHARIA E AS ATUAIS DIRETRIZES CURRICULARES NACIONAIS: o modelo didático da matemática em contexto como possível estratégia
}

\author{
Gabriel Loureiro de Lima \\ Pontifícia Universidade Católica de São Paulo - PUC-SP, Brasil \\ Barbara Lutaif Bianchini \\ Pontifícia Universidade Católica de São Paulo - PUC-SP, Brasil \\ Eloiza Gomes \\ Instituto Mauá de Tecnologia - IMT, Brasil \\ Juliana Martins Philot \\ Instituto Mauá de Tecnologia - IMT, Brasil
}

\begin{abstract}
Resumo
O objetivo deste artigo, que do ponto de vista metodológico contempla aspectos de uma pesquisa documental e bibliográfica, é apresentar perspectivas trazidas pelo Modelo Didático da Matemática em Contexto (MoDiMaCo), vinculado à Teoria A Matemática no Contexto das Ciências, para auxiliar no desenvolvimento da Matemática na formação do futuro engenheiro, de maneira a atender às exigências presentes nas novas Diretrizes Curriculares Nacionais (DCN) para a Graduação em Engenharia. Visando cumprir a meta de comparar diferentes estratégias preconizadas no MoDiMaCo com o que é estabelecido nas DCN, analisamos, sinteticamente, o cenário brasileiro da formação de engenheiros, refletimos acerca de alguns aspectos que norteiam as Diretrizes, discutimos a respeito das diferentes acepções para o termo competência, explicitando aquela com a qual trabalhamos e, por fim, apresentamos as principais características do MoDiMaCo. Identificamos contribuições do referido Modelo no que diz respeito às seguintes dimensões das Diretrizes: ao perfil do egresso; às atividades de aprendizagem visando o desenvolvimento das competências esperadas; à implantação de sistemas de acolhimento e nivelamento; e à avaliação das atividades desenvolvidas pelos estudantes.
\end{abstract}

Palavras-chave: Diretrizes Curriculares Nacionais para a Graduação em Engenharia; Teoria A Matemática no Contexto das Ciências; Modelo Didático da Matemática em Contexto.

\begin{abstract}
This article aims to integrate documental and bibliographical research in its methodological approach to present prospects based in the Didactic Model of Mathematics in Context (MoDiMaCo), linked to the Mathematics in the Science Contexts Theory, to break new ground towards Mathematics development regarding training of future engineer, fulfilling the requirements expected by the current National Curricular Guidelines of the Engineering Undergraduate Program (DCN). Committed to comparer the different strategies assumed in the MoDiMaCo as well as the DCN, we synthetically analyzed the Brazilian background of training of engineers, reflecting about some features that support the guidelines, arguing about the different meanings that could the word competence assume. We also explained the meaning that we choose to work and correlate with the main characteristics of the MoDiMaCo. We identified the contributions of the mentioned model regarding the followed dimensions from the guidelines: the profile of the graduated student; the learning activities aiming to develop expected competences; the implementation of hosting and leveling systems; and the grading of activities performed by students.
\end{abstract}

Keywords: National Curricular Guidelines of the Engineering Undergraduate Program; Mathematics in the Science Contexts Theory; Didactic Model of Mathematics in Context. 


\section{Introdução ${ }^{1}$}

A publicação da Resolução N² de 26 de abril de 2019 pela Câmara de Educação Superior (CES) do Conselho Nacional de Educação (CNE), que institui as atuais Diretrizes Curriculares Nacionais (DCN) do Curso de Graduação em Engenharia, traz desafios para as Instituições de Ensino Superior (IES) brasileiras que, até no máximo abril de 2022, precisarão reformular seus cursos de Engenharia de maneira a atender o que é preconizado nessas novas DCN.

Uma das principais tônicas nas atuais Diretrizes, que nas de 2002 estava presente de maneira bastante discreta, é a formação por meio do desenvolvimento de competências, ideia que, como destacamos em Lima et al. (2019) a partir das considerações presentes em Bianchini et al. (2017) tem se disseminado mundialmente desde a década de 1980 na organização de propostas curriculares, como, por exemplo, a recomendada pela Sociedade Europeia para a Formação de Engenheiros (Société Européenne pour La Formation des Ingénieurs) (SEFI).

Atrelada à ideia de educação por competências, nas atuais DCN destaca-se a importância de, ao longo de todo o processo formativo do futuro engenheiro, estimular a realização de atividades promovendo a integração e a interdisciplinaridade e articulando simultaneamente, a partir do contexto de aplicação do que está sendo estudado, a teoria e a prática. Além disso, o trabalho do estudante, tanto de maneira individual quanto em grupo, sob orientação do professor, deve ser estimulado e, como forma de promover uma educação que efetivamente esteja centrada no estudante, deve ser incentivado o uso de metodologias para aprendizagem ativa.

Busca-se, por meio da implementação das atuais Diretrizes, a formação de um egresso que, além de sólida formação técnica, tenha, dentre outros requisitos, visão holística e humanística; seja crítico, reflexivo, cooperativo e ético; atue de forma colaborativa e profissional em equipes; exerça, com proatividade, liderança em grupos de trabalho; reconheça e conviva com diversidades socioculturais em diferentes níveis e contextos; comunique-se eficientemente de forma oral, escrita e gráfica; seja capaz de modelar fenômenos utilizando, dentre outros recursos, ferramentas matemáticas, estatísticas, computacionais e de simulação; esteja apto a pesquisar, a utilizar novas tecnologias e a formular, analisar e resolver, de forma criativa, os problemas de Engenharia, adotando em sua prática perspectivas multidisciplinares e transdisciplinares; e que possa aprender, continuamente, por meio de uma atitude investigativa e autônoma.

Diante desse perfil de egresso explicitado nas atuais DCN, nos questionamos de que forma os professores de Matemática, podem contribuir, por meio de suas práticas, para a formação de um engenheiro com os requisitos esperados de um profissional desta área no contexto do século XXI, uma vez que tal componente curricular continua sendo básica para todas as habilitações.

Entendemos que um modelo didático específico, denominado Modelo Didático da Matemática em Contexto, desenvolvido no âmbito da Teoria A Matemática no Contexto das Ciências (TMCC) que é o referencial que tem fundamentado nossas investigações acerca dos 
processos de ensino e de aprendizagem de Matemática nos cursos de Engenharia, traz em seu bojo uma gama de possibilidades para, na formação do futuro engenheiro, trabalhar conteúdos matemáticos de maneira afinada ao que é preconizado nas atuais DCN.

A apresentação destas possibilidades trazidas pelo MoDiMaCo para abordar a Matemática na Engenharia, de forma a contribuir para o desenvolvimento dos requisitos os quais, conforme estabelecido nas DCN, são exigidos dos egressos, é o objetivo central deste artigo que, do ponto de vista metodológico, caracteriza-se como uma investigação que, para a coleta de dados, combina aspectos da pesquisa documental e da pesquisa bibliográfica, na acepção de Marconi e Lakatos (2003). Segundo os autores, a pesquisa documental tem como principal característica a coleta de dados a partir de documentos (fontes primárias). No caso desta pesquisa, os documentos a que recorremos são o Parecer $\mathrm{N}^{\circ} 1 / 2019$ (BRASIL, 2019a) e a Resolução N²/2019 (BRASIL, 2019b), ambos do Conselho Nacional de Educação/Câmara de Educação Superior. A pesquisa bibliográfica, por sua vez, caracterizase pela coleta de dados realizada a partir de fontes secundárias, ou seja, por meio da "bibliografia já tornada pública em relação ao tema de estudo" (MARCONI; LAKATOS, 2003, p. 183). No caso da investigação que relatamos neste artigo, recorremos a algumas publicações acerca de Educação por Competências (BIANCHINI et al. (2017); CAMARENA (2011)), da Teoria A Matemática no Contexto das Ciências e, em especial, de seu modelo didático, o MoDiMaCo (CAMARENA (1984; 1995; 1999; 2010; 2013a; 2014; 2017), GOMES et al (2018a; 2018b; 2019), LIMA; BIANCHINI; GOMES (2016; 2018; 2019a; 2019b)).

Para atingir o objetivo central anteriormente anunciado, entendemos como essencial apresentar algumas considerações preliminares acerca do cenário brasileiro da formação de engenheiros e aspectos norteadores das atuais DCN, da ideia de Educação por Competências, da Teoria A Matemática no Contexto das Ciências e especificamente do Modelo Didático da Matemática em Contexto. É o que apresentamos nas seções seguintes para, posteriormente, a partir da base de conhecimentos construída, discutirmos as potencialidades do MoDiMaCo para trabalhar com a Matemática nos cursos de Engenharia de maneira consonante ao que é preconizado nas Diretrizes atuais. 


\section{O cenário brasileiro da formação de engenheiros e aspectos norteadores das atuais Diretrizes Curriculares Nacionais}

Para a caracterização do cenário brasileiro da formação de engenheiros apresentada nesta seção, tomamos com referência os dados presentes no Parecer $N^{\circ} 1 / 2019$ do Conselho Nacional de Educação/Câmara de Educação Superior, homologado em 23 de abril de 2019. Tal parecer tem como assunto as Diretrizes Curriculares Nacionais do Curso de Graduação em Engenharia e foi elaborado por uma comissão composta por profissionais de diferentes áreas de formação.

De acordo com o que consta no Parecer CNE/CES No1/2019, a primeira Escola de Engenharia do Brasil, a Real Academia de Artilharia, Fortificação e Desenho, foi criada em 1792 na cidade do Rio de Janeiro; a segunda, a Escola de Minas, foi fundada em Ouro PretoMG, em 1876.

Com a proclamação da República, foram criadas mais 13 escolas de Engenharia no país até 1950, perfazendo então 16 escolas de Engenharia com cerca de 70 cursos em funcionamento, abrangendo apenas 8 estados da Federação. A partir de 1950 houve significativo crescimento do número de cursos, no entanto, a grande expansão ocorreu a partir da segunda metade da década de 90 , coincidindo com a edição da nova Lei de Diretrizes e Bases da Educação Nacional (Lei n ${ }^{\circ}$ 9.394/1996) (BRASIL, 2019a, p. 8).

Pela leitura dos dados apresentados no referido documento, destaca-se que "até o início deste século, a maioria dos cursos de Engenharia eram de IES públicas. Atualmente, mais de $75 \%$ dos cursos estão em IES privadas" (p. 8). Ressalta-se ainda que, em 2018, havia 6.106 cursos de Engenharia registrados no país, "sendo 5.816 na modalidade presencial e 290 na modalidade EaD, com funcionamento em 1.176 IES distintas" (Idem). Além da expansão em relação ao número de cursos ofertados, observou-se nos últimos anos também um aumento no número de habilitações da Engenharia. Salienta-se que, tomando como referência a primeira denominação do curso (Mecânica, Elétrica, Civil, de Produção, etc.), enquanto no início dos anos 2000 havia cerca de 40 habilitações de Engenharia registradas, hoje são em torno de 60. "Quando se considera a segunda denominação ou ênfase (Civil de Construção, Elétrica de Potência, Mecânica Automobilista) são encontrados (no Brasil) mais de 250 registros de denominações distintas para o curso de Engenharia" (BRASIL, 2019a, p. 9). Para os autores do Parecer, essa expansão em termos de habilitações e ênfases dos cursos de Engenharia evidencia que há uma preocupação, no país, em acompanhar o desenvolvimento tecnológico e novas áreas passaram a ser tratadas no âmbito do campo de atuação da Engenharia, como, por exemplo a Saúde e a Biologia presentes, dentre outras, na habilitação Engenharia Biomédica.

As habilitações mais ofertadas no país, tanto presencialmente como na educação a distância, são aquelas relacionadas à infraestrutura (Civil, Elétrica, Mecânica, etc.), em razão, segundo o supracitado Parecer, deste setor ser o que mais emprega o conhecimento de Engenharia no Brasil. Outro dado relevante para a caracterização do cenário da Engenharia 
no país diz respeito ao crescimento, nas últimas duas décadas, do número de cursos de Engenharia de Produção, que "pode ser explicado pela necessidade de melhorias no sistema produtivo em termos de produtividade e competitividade". (BRASIL, 2019a, p. 11). Por sua vez, "os cursos mais voltados à tecnologia de ponta (Computação, Controle e Automação, Software etc.) são menos numerosos, o que é representativo do atual estágio brasileiro de importador de tecnologia" (Idem).

O número de matriculados e concluintes nos cursos de Engenharia também tem aumentado no país. Enquanto em 1991 foram 12.332 novos engenheiros formados (6.141 de IES públicas e 6.191 de IES privadas), dez anos depois foram 17.811 (9.558 de IES públicas e 8.253 de IES privadas). De 2002 ao final de 2017, observou-se que a quantidade de engenheiros formados por ano mais do que quintuplicou, havendo, por exemplo, em 2016 a formação de 100 mil bacharéis nesta área no Brasil. (BRASIL, 2019a).

Apesar dos dados apresentados evidenciarem, especialmente nas duas últimas décadas, expansão no número de cursos de Engenharia ofertados no país, do número de habilitações destes cursos e, consequentemente, do número de áreas do conhecimento que passam a ser tratadas sob a ótica da Engenharia, e ainda do número de engenheiros formados, há uma série de questões a serem enfrentadas na formação destes profissionais no Brasil.

Segundo explicitado no Parecer CNE/CES N¹/2019, entre 2011 e 2016 o Brasil perdeu 22 posições no Índice Global de Inovação (IGI), ranking elaborado pela Universidade de Cornell, a INSEAD Business School e pela Organização Mundial da Propriedade Intelectual (OMPI), ocupando, em 2017, a 69 $9^{a}$ colocação entre os 128 países avaliados. Em 2019 (versão mais recente do IGI), foram 129 países avaliados, alcançando o Brasil a $66^{a}$ posição, tendo perdido duas posições em relação a 2018 (UNIVERSIDADE CORNELL; INSEAD; OMPI, 2019). Um dos indicadores do IGI relacionados aos recursos humanos e à pesquisa é exatamente graduados em ciência e engenharia. Em relação a este indicador, na publicação em que são apresentados os resultados do IGI de 2018, explicita-se que: "o Brasil apresenta um desempenho relativamente fraco nos subpilares de Ambiente de Negócios e Crédito e, em particular, em indicadores como facilidade para abrir uma empresa, resultados do PISA, graduados em ciências e engenharia..." (UNIVERSIDADE CORNELL; INSEAD; OMPI, 2018, p. 83). Países melhores colocados costumam ter posições de destaque em relação ao indicador graduados em ciência e engenharia. Como consequência de ocupar posições menos privilegiadas em rankings como este, o Brasil acaba enfrentando dificuldades para competir no mercado internacional.

Outra questão apontada no Parecer CNE/CES Nº1/2019 é, mesmo com o aumento do número de formados em Engenharia nos últimos anos, a baixa quantidade de engenheiros por habitante observada no Brasil. Segundo dados da Organização para a Cooperação e Desenvolvimento Econômico (OCDE) enquanto que Coreia, Rússia, Finlândia e Áustria, em 2014, apresentavam a proporção de 20 engenheiros para cada 10 mil habilitantes, "países como Portugal e Chile dispunham de cerca de 16 engenheiros para cada 10 mil habitantes, enquanto o Brasil registrava somente 4,8 engenheiros para o mesmo quantitativo" (BRASIL, 2019a, p. 1). 
Um dado bastante importante a ser considerado é a taxa de evasão presente nos cursos de Engenharia do país, que permanece em torno de 54\% segundo os autores do referido Parecer. Observa-se que dos ingressantes nas diferentes habilitações de Engenharia, "quase a metade desiste do curso, sendo que esta evasão ocorre majoritariamente nos dois primeiros anos do curso, quando a maioria dos cursos oferecem as chamadas disciplinas básicas" (BRASIL, 2019a, p. 18).

Além disso, por meio do supracitado Parecer, destaca-se que:

O setor produtivo encontra dificuldades para recrutar trabalhadores qualificados para atuar na fronteira do conhecimento das engenharias, que, para além da técnica, exige que seus profissionais tenham domínio de habilidades como liderança, trabalho em grupo, planejamento, gestão estratégica e aprendizado de forma autônoma, competências conhecidas como soft skills. Em outras palavras, demanda-se crescentemente dos profissionais uma formação técnica sólida, combinada com uma formação mais humanística e empreendedora (BRASIL, 2019a, p. 2).

Evidencia-se, portanto, a necessidade de repensar a formação do futuro engenheiro de forma a lhes possibilitar o desenvolvimento de requisitos exigidos para o profissional do futuro, sendo estes avaliados, por exemplo, em rankings como o IGI, e também de buscar estratégias para reduzir, especialmente nos primeiros anos, a taxa de evasão nos cursos de Engenharia brasileiros. A este respeito, os autores do Parecer CNE/CES Nº1/2019 ressaltam que:

Tendo em vista o lugar central ocupado pela Engenharia na geração de conhecimento, tecnologias e inovações, é estratégico considerar essas novas tendências e dar ênfase à melhoria da qualidade dos cursos oferecidos no país, a fim de aumentar a produtividade e ampliar as possibilidades de crescimento econômico, tanto hoje quanto no futuro. A revisão das Diretrizes Nacionais do Curso de Graduação em Engenharia é peça-chave deste processo (BRASIL, 2019a, p. 2).

Tendo-se apresentado esse breve panorama a respeito do cenário da formação de engenheiros no Brasil e se evidenciado a necessidade de repensar os cursos de maneira a reduzir as taxas de evasão, mas principalmente melhorar a qualidade da formação ofertada a fim de possibilitar que os egressos possam desenvolver as competências indispensáveis a um profissional da Engenharia requerido no contexto do século XXI, passamos a apresentar algumas considerações acerca das atuais Diretrizes Curriculares Nacionais do Curso de Graduação em Engenharia e de seus aspectos norteadores. Essas DCN são resultado de um amplo trabalho de revisão das de 2002, trabalho este que, como salientado no último trecho citado do Parecer CNE/CES Nº1/2019, é tido como peça-chave nesse urgente processo de repensar a formação do engenheiro no Brasil.

Como bem resume o Parecer CNE/CES Nº1/2019, a revisão das Diretrizes Curriculares Nacionais do Curso de Graduação em Engenharia, que haviam sido homologadas em 2002, 
foi desencadeada pela "necessidade de atualizar a formação em Engenharia no país, visando atender às demandas futuras por mais e melhores engenheiros" (BRASIL, 2019a, p. 1).

Mas, para compreendermos a importância desse processo de construção de novas DCN para a Engenharia, é fundamental termos clareza a respeito do papel dessas Diretrizes. Para esse esclarecimento, recorremos mais uma vez ao Parecer CNE/CES Nº1/2019. De acordo com este documento, as Diretrizes

[...] são normas que orientam o projeto e o planejamento de um curso de graduação. Disso depreende-se que as diretrizes nacionais curriculares devem encerrar necessariamente certa flexibilidade para se adequar aos diversos contextos espaciais e temporais, sem tolher, no entanto, a melhoria contínua ou a inserção de inovações decorrentes, por exemplo, de novas tecnologias e metodologias. Ao contrário, as diretrizes nacionais curriculares devem servir de incentivo a essas ações inovadoras. Nesse sentido, diante das profundas transformações que estão em andamento no mundo da produção e do trabalho (em especial, com a emergência da manufatura avançada), as DCN devem ser capazes de estimular a modernização dos cursos de Engenharia (BRASIL 2019a, p. 2).

Além disso, no mesmo documento explicita-se que, "para estabelecer diretrizes curriculares inovadoras, projetar e implementar novos currículos para os cursos de Engenharia, é preciso, portanto, pensar na formação do profissional da área, de forma que seja ele capaz de atuar em trajetórias muitas vezes imprevisíveis" (p. 3). Deve-se, por meio das DCN de um curso de Engenharia, estimular-se: a atualização contínua do curso, a possibilidade do estudante assumir o papel de protagonista na construção de seu próprio conhecimento, uma maior integração entre as IES e as empresas, a valorização da interdisciplinaridade e do papel do professor como agente de transformações dentro e fora da sala de aula (BRASIL, 2019a).

Tendo-se compreendido qual a função das DCN e como elaborar um documento que seja inovador, é relevante ter clareza a respeito das premissas que, conforme indicado no Parecer CNE/CES N¹/2019, guiaram o processo de revisão das DCN de 2002 que deu origem às Diretrizes atuais. São elas:

(i) elevar a qualidade do ensino em Engenharia no país; (ii) permitir maior flexibilidade na estruturação dos cursos de Engenharia, para facilitar que as instituições de ensino inovem seus modelos de formação; (iii) reduzir a taxa de evasão nos cursos de Engenharia, com a melhoria de qualidade; e (iv) oferecer atividades compatíveis com as demandas futuras por mais e melhores formação dos engenheiros (BRASIL, 2019a, p. 3).

A partir dessas premissas, foram construídas Diretrizes tendo, dentre seus aspectos norteadores alguns que, por estarem mais diretamente relacionados ao objetivo da pesquisa relatada neste artigo, são por nós destacados: a valorização de um caráter social na formação a ser dada ao futuro engenheiro; o estabelecimento de um currículo por competências desenvolvidas ao longo de todo o processo formativo; a previsão de programas de 
acolhimento contemplando nivelamento de conhecimentos, atendimento psicopedagógico, entre outros; a valorização de estratégias cujo foco sejam o desenvolvimento das competências, tanto as de caráter geral quanto as de caráter específico de determinada habilitação de Engenharia; o incentivo à adoção de estratégias de ensino e de aprendizagem que valorizem a integração e a exploração dos conteúdos a partir de situações-problema reais ou simulados da prática profissional; a valorização de metodologias para aprendizagem ativas; o estímulo à utilização de tecnologias da informação, à aprendizagem colaborativa, ao trabalho em equipe, à interdisciplinaridade e à transdisciplinaridade; os estudantes devem se tornar protagonistas na construção de seus próprios conhecimentos; o professor deve assumir o papel de mediador e tutor; a avaliação deve ser contínua; o estímulo à utilização de instrumentos e estratégias de avaliação que possibilitem a identificação de obstáculos e dos possíveis meios para superá-los; e a valorização de atividades de contextualização em parceria com empresas e organizações.

Para que possamos relacionar esses aspectos norteadores das DCN ao MoDiMaCo, é fundamental, inicialmente, compreendermos o que é a Educação por Competências (que está no cerne da organização curricular proposta nas atuais Diretrizes) e as principais características do referido Modelo Didático. São a estes objetivos que, reciprocamente, nos atemos nas duas seções seguintes.

\section{A Educação por Competências}

As considerações presentes nesta seção têm como fonte principal o artigo de Bianchini et al. (2017), intitulado Competências matemáticas: perspectivas da SEFI e da MCC, no qual os autores apresentam os resultados de uma detalhada pesquisa bibliográfica que realizaram acerca da temática Educação por Competências, tendo como foco principal reflexões a respeito do tema nos cursos de Engenharia.

Bianchini et al. (2017) afirmam, com base em pesquisas de Vargas, Steffen e Brígido (2002) e García (2011) que a origem da noção de competência está diretamente vinculada às indústrias e à ideia de competência profissional, tendo esta última se desenvolvido a partir dos anos 1960 em países como Estados Unidos, Canadá e Inglaterra que, na ocasião, estavam preocupados em aperfeiçoar a relação entre os sistemas educativo e produtivo de forma a, efetivamente, educar e capacitar a mão de obra requerida. Mas, para compreendermos de fato o que é Educação por Competências, precisamos ter clareza a respeito da própria noção de competência.

Segundo Camarena (2011, p. 88) citada por Bianchini et al. (2017), "o conceito de competências está submetido a processos contínuos de definição e redefinição, tanto em termos de pequenas nuances terminológicas, quanto em razão dos tratamentos diferenciados dados a ele em cada país". A autora afirma que uma análise detalhada de diferentes concepções do termo competência evidencia aspectos comuns a todos os autores, o que ela denominou de componentes das competências e que são: conhecimentos, habilidades, atitudes e valores. Para Camarena (2011) são componentes que podem ser consideradas 
gerais pelo fato dos tipos de conhecimentos, habilidades, atitudes e valores, a serem desenvolvidos, dependerem das especificidades de determinada carreira profissional. Além de diferentes acepções, o termo competência também é aplicado em âmbitos distintos. Neste artigo, vamos nos restringir à sua aplicação na Educação, mais especificamente à ideia de Educação por Competências. Mas, antes de efetivamente entrarmos nessa questão, precisamos evidenciar a concepção de competências que adotamos.

A análise detalhada tanto das Diretrizes para a Engenharia de 2002, que já faziam referência às competências, quanto das atuais, aprovadas em 2019, nas quais essa noção ganha importância capital, evidencia que, em momento algum, há nos documentos uma definição acerca do que está sendo entendido por competência. No entanto, aspectos reveladores da concepção segundo a qual o referido termo está sendo adotado podem ser identificados em dois trechos do Parecer CNE/CES Nº1/2019. O primeiro deles diz respeito ao perfil do egresso a ser buscado, que deve "se voltar para uma visão sistêmica e holística de formação, não só do profissional, mas também do cidadão-engenheiro, de tal modo que se comprometa com os valores fundamentais da sociedade na qual se insere (BRASIL, 2019a, p. 25 - grifo nosso). O segundo, por sua vez, evidencia a diferença entre uma organização curricular tradicional por conteúdos daquela por competências, que "pressupõe a substituição da lógica da assimilação prévia dos conteúdos - para posterior incorporação e uso -, pela ocorrência concomitante desta com o desenvolvimento de habilidades e atitudes a partir de conhecimentos específicos" (BRASIL, 2019a, p. 26 - grifos nossos).

A partir destes dois trechos do Parecer CNE/CES Nº1/2019 salientados no parágrafo anterior, percebemos que a concepção do termo competência implicitamente assumida na elaboração das atuais Diretrizes para os cursos de Engenharia é muito próxima, do ponto de vista semântico, da estabelecida por Camarena (2011) no âmbito da Teoria A Matemática no Contexto das Ciências (TMCC) na qual se insere o MoDiMaCo.

Uma vez que neste artigo nosso objetivo é o de estabelecer um diálogo entre o MoDiMaCo e as DCN, é exatamente essa definição de competência proposta por Camarena na esfera da TMCC que assumimos: "as competências são os alicerces do futuro profissional para enfrentar uma situação-problema fazendo uso da integração de toda sua bagagem de conhecimentos, habilidades, atitudes e valores que são mobilizados em suas estruturas cognitivas" (CAMARENA, 2011, p. 114 - grifos nossos). A respeito dessas componentes das competências, Camarena afirma que:

[...] quando nos referimos a conhecimentos, o que desejamos é que os futuros profissionais tenham os conhecimentos que serão requeridos em suas vidas laboral e profissional, porém não somente isso, mas que saibam aplica-los e possam realizar procedimentos com eles; e neste sentido, o realizar procedimentos está relacionado com as habilidades. Desenvolver habilidades de aplicação do conhecimento é importante, porém não somente essas habilidades são as desejadas; devem ser desenvolvidas também habilidades de comunicação, de análise, de autonomia, o fazer com saber, entre outras. As atitudes que são consideradas giram em torno de ter predisposição ao entendimento interpessoal, atitude de cooperação, de autonomia, etc.; em geral, há muitos outros elementos que podem ser considerados 
no âmbito dessa componente. O mesmo ocorre para a componente valores, na qual se faz referência, entre outros, à honestidade, à responsabilidade e ao "bom comportamento" (CAMARENA, 2011, p. 106).

Tendo explicitado a concepção de competência que assumimos neste artigo, passamos a apresentar algumas características acerca da Educação por Competências.

Vargas, Steffen e Brígido (2002, p. 92), citados por Bianchini et al. (2017), conceitualizam Educação por Competências como um "enfoque sistêmico sobre o desenvolvimento e formação profissional. A educação se inicia com a identificação do que se espera que o estudante seja capaz de fazer ao final do programa (curso)". Para Perrenoud (2000), também citado por Bianchini et al. (2017), por meio da Educação por Competências, busca-se possibilitar ao estudante não apenas construir conhecimentos, mas também saber mobilizá-los em situações reais de seu cotidiano profissional. E uma noção que se torna essencial para atingir esse objetivo é a de "contextualização dos conteúdos, em substituição à suposta insularização dos saberes organizados e divididos em disciplinas justapostas" (ARAÚJO, 2001, p. 51 apud BIANCHINI et al., 2017, p. 59). Ainda conforme destaca Araújo (2001, p. 51) apud Bianchini et al. (2017) "a redefinição dos conteúdos é marcada, de um lado, pela sua maior implicação com uma utilidade e sua vinculação com situações definidas que requerem saberes e saber-fazer e, de outro lado, pela sua maior valorização social".

Bianchini et al. (2017, p. 60) citam ainda as ideias de Pinheiro e Burini (2006, p. 160), segundo as quais "nos cursos tradicionais, denominados conteudistas, [...] a formação profissional dos estudantes fica condicionada à percepção individual de seus professores sobre o curso, não existindo uma integração continuada dos saberes desenvolvidos por cada professor em suas disciplinas". Na Educação por Competências, por sua vez, a premissa é "o aprendizado baseado em problemas, ou em projetos. Para isso, é necessário escolher situações-problema, para que os estudantes possam adequadamente desenvolver suas competências" (Idem).

Neste artigo, retomamos, detalhamos e aprofundamos a ideia que originalmente apresentamos em Lima et al. (2019), de que, nos cursos de Engenharia a serem implementados a partir das atuais DCN, conduzir os processos de ensino e de aprendizagem de Matemática em consonância aos preceitos do MoDiMaCo, revela-se como uma das possibilidades de, no âmbito desta ciência básica da Engenharia, contribuir, durante todo o processo de formação do futuro engenheiro, para o desenvolvimento de competências que lhes serão requeridas posteriormente em sua atuação profissional. Para que essa ideia possa efetivamente ser compreendida, na próxima seção apresentamos os principais pressupostos da Teoria A Matemática no Contexto das Ciências e do MoDiMaCo, modelo didático a ela atrelado. 


\section{O Modelo Didático da Matemática em Contexto (MoDiMaCo)}

A Teoria A Matemática no Contexto das Ciências (TMCC) começou a ser desenvolvida em 1982, no Instituto Politécnico Nacional do México, pela pesquisadora Patricia Camarena. Tal referencial insere-se na linha de investigação da Matemática Social, também desenvolvida pela mencionada pesquisadora. A Matemática Social, de caráter multidisciplinar, uma vez que contempla em suas reflexões elementos das áreas de Educação, Psicologia, Sociologia, Antropologia e Filosofia, concentra investigações referentes tanto aos processos de ensino quanto aos ambientes de aprendizagem de Matemática no nível universitário, tendo em vista a formação integral do estudante e o desenvolvimento de competências. Objetiva-se, por meio de pesquisas na linha da Matemática Social, compreender como a Matemática trabalhada nos cursos de graduação pode contribuir para a formação de um profissional capaz de estabelecer de maneira eficiente a vinculação entre esta ciência e a profissão que exerce (CAMARENA 1984; 1999; 2014). Como tendência ideológica, por meio da Matemática Social defende-se que os professores não somente cumpram os programas de ensino planejados, mas que os analisem criticamente, questionando a respeito do porquê ensinar cada um dos conteúdos elencados, reflitam a respeito de como ensiná-los de maneira a serem significativos para os estudantes e para que estes possam aplica-los em suas futuras práticas profissionais.

Por estar atrelada à linha de investigação citada no parágrafo anterior, a TMCC é uma teoria educativa que obviamente contempla um caráter social. Está fundamentada, segundo Camarena (2013a), nos seguintes três paradigmas: (i) a Matemática é uma ferramenta de apoio e uma disciplina formativa para os profissionais; (ii) a Matemática tem uma função específica no nível universitário; e (iii) os conhecimentos nascem integrados. O pressuposto filosófico educacional da Teoria é que o estudante, ao concluir um curso de graduação no qual a Matemática está à serviço, mas não é um objeto de estudo, como é o caso, por exemplo, da Engenharia, seja capaz de transferir os conhecimentos da Matemática para as áreas que os requerem e com isso o desenvolvimento de competências profissionais e laborais seja favorecido, bem como a formação integral do estudante.

Segundo Camarena (2017), na ótica da TMCC, o ambiente de aprendizagem é visto

[...] como um sistema complexo do tipo social, cultural, econômico, político e psicológico no qual se fazem presentes as cinco fases da teoria, que interatuam entre si, não são isoladas uma das outras e, além disso, em cada fase estão incluídas formas teórico-metodológicas de trabalho. Quer dizer, como teoria, em cada uma de suas fases se incluem metodologias com fundamento teórico em acordo com os paradigmas nos quais se sustenta a teoria, por meio das quais, dentre outros, se estabelecem os passos para o desenho curricular, se descreve a didática a seguir, se explica o funcionamento cognitivo dos alunos e se proporcionam elementos acerca dos saberes matemáticos vinculados às atividades dos profissionais (CAMARENA, 2017, p. 2). 
As cinco fases da TMCC às quais se faz referência na citação anterior são denominadas: curricular, epistemológica, docente, didática e cognitiva. Lima, Bianchini e Gomes (2019a) apresentam, de maneira sintética, uma caracterização de cada uma dessas fases.

Na fase curricular o principal objetivo é a construção, por meio da metodologia Dipcing, de um currículo de Matemática para a graduação em questão que seja objetivo e valorize a vinculação curricular interna (entre as disciplinas matemáticas e não matemáticas do curso), a vinculação curricular externa (entre a educação básica e a graduação e entre a graduação e a pós-graduação), assim como a vinculação entre a universidade e o futuro cotidiano profissional do estudante. A fase didática contempla o Modelo Didático da Matemática em Contexto (MoDiMaCo), que tem como principal ferramenta de trabalho os eventos contextualizados (problemas ou projetos que desempenham papeis de entes integradores entre disciplinas matemáticas e não matemáticas). $\mathrm{Na}$ fase epistemológica o objetivo principal é compreender como, do ponto de vista epistemológico estão relacionados a Matemática e problemas específicos de outras áreas do conhecimento que necessitam das ferramentas dessa ciência. Também no âmbito desta fase considera-se aquilo que Camarena (2001) denomina de transposição contextualizada, constructo teórico por meio do qual busca-se analisar como a Matemática aprendida pelos estudantes sofre transformações para adaptarse ao que é requerido por outras ciências. Na fase docente busca-se estruturar como formar o professor para trabalhar com o currículo construído na fase curricular. $\mathrm{Na}$ fase cognitiva a sustentação teórica principal é a Aprendizagem Significativa de Ausubel (1990), mobilizada para analisar, sob o ponto de vista cognitivo, o trabalho dos estudantes no MoDiMaCo (LIMA; BIANCHINI; GOMES, 2019a. p. 189).

Neste artigo, em função do objetivo visado, apresentamos um maior detalhamento apenas da fase didática e especialmente do modelo didático a ela vinculado, o Modelo Didático da Matemática em Contexto (MoDiMaCo).

O MoDiMaCo é descrito por Camarena (2010) como um processo didático-metodológico a ser empregado tendo como principal objetivo permitir que o estudante de cursos de graduação nos quais a Matemática é uma ferramenta - e não o objeto principal de estudo perceba, sem recorrer a aplicações artificiais, utilizando as notações requeridas na área de conhecimento na qual o estudante está se formando e de forma não árida, como a Matemática está vinculada aos seus interesses. Por meio da abordagem a ser adotada, deve-se buscar que os graduandos, motivados, desenvolvam sua autonomia e construam seus próprios conhecimentos, de forma estruturada e não fracionada, com amarras firmes, duradouras e, principalmente, que desenvolvam habilidades para transferir os conhecimentos da Matemática para as áreas nos quais eles serão aplicados. Esse processo didático-metodológico está estruturado, segundo Camarena (2010; 2013a), em três blocos:

- $1^{\circ}$ bloco - Didática do Contexto: Por meio de um trabalho em sala de aula recorrendo ao que Camarena (2013a) entende por Didática do Contexto e denomina de Matemática em Contexto, a qual será detalhada nos parágrafos seguintes, estabelecer a vinculação entre as disciplinas matemáticas e não matemáticas do curso a partir de problemas ou projetos, 
denominados eventos contextualizados, diretamente relacionados à futura área de atuação profissional do estudante;

- $2^{o}$ bloco - Cursos Extracurriculares: ministrar aos graduandos cursos extracurriculares nos quais serão realizadas atividades para auxiliá-los no desenvolvimento de habilidades metacognitivas, de pensamento e em utilizar heurísticas na resolução de problemas e também atividades para bloquear crenças negativas que possam atrapalhá-los nas resoluções dos eventos contextualizados;

- $3^{\circ}$ bloco - Oficinas Interdisciplinares Abrangentes: ministrar aos graduandos, nos últimos semestres do curso, oficinas que sejam abrangentes e interdisciplinares nas quais o objetivo central seja a resolução de problemas reais da profissão, trazidos, por exemplo pelas empresas, indústrias ou outros tipos de organizações nas quais os egressos poderão atuar como profissionais.

Passamos então, na sequência, a apresentar aqueles detalhes de cada um desses três blocos que, posteriormente, relacionaremos às atuais DCN.

No $1^{\circ}$ bloco, há uma didática específica (a qual Camarena (2013a) se refere como Didática do Contexto) a ser adotada em sala de aula. A esta, a autora dá o nome de Matemática em Contexto. Por ter sido construída a partir da TMCC, a Matemática em Contexto é uma didática teoricamente embasada e não uma proposta experimental. Como destacam Lima, Bianchini e Gomes (2019b) a partir das ideias de Camarena (2017), a didática da Matemática em Contexto é do tipo construtivista e tem como pilares os seguintes enfoques:

(i) Psicogenético de Piaget - "para a construção do conhecimento, a pessoa deve passar do concreto para o abstrato"; (ii) Sociocultural de Vygotsky - "para a aprendizagem deve haver especial ênfase na aprendizagem colaborativa, o que demanda um docente mediador"; (iii) Cognitivo de Aprendizagem Significativa de Ausubel - "a aprendizagem é uma relação substantiva entre o conhecimento novo e o conhecimento prévio que possui o indivíduo; a aprendizagem é essencialmente ativa" (LIMA; BIANCHINI; GOMES, 2019b, p. 137).

A Matemática em Contexto é organizada, conforme explicita Camarena (2010; 2013a), em torno de dois eixos: a contextualização (momento em que os conceitos são abordados de maneira interdisciplinar a partir de contextos diferentes da Matemática) e a descontextualização (em que os conceitos são trabalhados somente no contexto da Matemática, com níveis de rigor e formalismo adequados à área de formação do graduando).

No eixo da contextualização, a principal estratégia é, segundo Camarena (2013a), apresentar ao estudante "uma matemática interdisciplinar, contextualizada em fontes científicas e sociais" (p. 27). Isso deve ser feito por meio do que a autora denomina de eventos contextualizados que são, conforme definem Lima, Bianchini e Gomes (2016) a partir de Camarena (2013a), problemas ou projetos desenvolvidos com o objetivo de, por meio de um trabalho interdisciplinar no ambiente de aprendizagem, integrar as disciplinas matemáticas e as não matemáticas que compõem um currículo de um curso no qual a Matemática está a serviço, como é o caso da Engenharia. 
Os eventos contextualizados podem ser construídos a partir de três fontes de contextualização: as demais disciplinas que o graduando cursa ou irá cursar, as atividades da vida laboral e profissional e as atividades da vida cotidiana. É importante ressaltar, como destaca Camarena (1995), que os eventos contextualizados não são exercícios, problemas ou projetos rotineiros. Ao ler o enunciado do evento, o estudante deverá ser posto frente a uma situação de conflito cognitivo, deve ficar intrigado e motivado para executar a tarefa dada. Nada é dito ao estudante, nesse enunciado, no sentido do que ele deverá fazer; a compreensão do evento é que o permitirá iniciar seu processo de resolução. Nos eventos, os conceitos nunca aparecem de maneira isoladas; estão presentes sempre em rede e, consequentemente, de maneira interrelacionada. Como frisa Camarena (2013a), os eventos podem ser construídos com diferentes intenções: realizar diagnósticos, motivar, introduzir conceitos novos, construir conhecimentos, avaliar, etc. Exemplos de eventos contextualizados podem ser encontrados em Gomes et al. (2018a, 2018b, 2019).

Os eventos contextualizados são solucionados por equipes compostas por três estudantes que atuam de maneira colaborativa. Compõem essas equipes, como esclarecem Lima, Bianchini e Gomes (2018) a partir de Camarena (2017), um líder emocional, um líder intelectual e um líder operativo, cada um deles com características complementares para a realização de um trabalho efetivamente colaborativo. "O líder emocional é aquele que motiva a equipe, o líder intelectual é um estudante reflexivo, analítico, com conhecimentos prévios bem construídos e o líder operativo é aquele que, como a própria nomenclatura indica, executa efetivamente tarefas como, por exemplo, resolver equações, expor os argumentos da equipe para a classe, etc." (LIMA; BIANCHINI; GOMES, 2018, p. 120). A identificação desses líderes é feita por meio de um instrumento denominado Questionário Honey-Alonso de Estilos de Aprendizagem (CHAEA), composto por quatro seções com 20 perguntas cada, sendo que cada seção corresponde a um dos quatro grupos de estilos de aprendizagem de Kolb (reflexivo $(\mathrm{R})$, pragmático $(\mathrm{P})$, ativo $(\mathrm{A})$ e teórico $(\mathrm{T})$ ). A partir das respostas dadas pelos estudantes a essas 80 questões, o docente deve construir uma planilha com a pontuação de cada um deles, atribuindo, para cada estudante, um ponto para cada resposta sim e nenhum ponto para cada resposta não. Deverá ser computada a pontuação em cada um dos quatro grupos de questões (denotaremos essas pontuações por R, P, A e T). Em seguida, deve ser calculada a média dos pontos obtidos por cada um dos estudantes nos grupos de questões relacionados aos estilos reflexivo e teórico (denotaremos essa pontuação por M). Finalmente, deve-se comparar as pontuações de cada estudante em P, A e M. Se a pontuação for maior em P, o estudante será um líder operativo; se for maior em A, será um líder emocional e se for maior em M, será um líder intelectual. Em caso de empate, caberá ao professor analisar o conjunto de estudantes com os quais ele irá trabalhar para decidir em qual liderança (dentre aquelas em que sua pontuação foi igual) o estudante poderá melhor contribuir com o grupo.

Compostas as equipes, deve-se deixar claro a cada uma delas o que está sendo esperado por meio trabalho que começará a ser realizado e o que, de fato, significa trabalhar em equipes colaborativas. Então o evento contextualizado é entregue às equipes e estas, caso tais eventos não tenham função diagnóstica ou de avaliação, podem, em seguida, conforme postula Camarena (2017), atuar livremente. Elas 
têm total liberdade para interagirem umas com as outras, trocarem ideias sobre estratégias de resolução, fazer consultas a obras, na biblioteca, por exemplo, para compreenderem algo que não conhecem ou esclarecerem dúvidas, consultar o professor, etc. As tecnologias podem, a não ser em casos específicos em que isso infrinja os objetivos estabelecidos pelo docente, ser utilizadas como ferramentas de apoio durante o trabalho com os eventos contextualizados (LIMA; BIANCHINI; GOMES, 2018, p. 120).

Camarena (2017) sintetiza, em termos metodológicos, por meio dos seguintes passos, o primeiro bloco do MoDiMaCo:

Os estudantes resolvem em classe um evento contextualizado; o docente introduz atividades de aprendizagem no momento que os estudantes as requererem. Quando os alunos terminam a resolução do evento, o professor apresenta à classe o conceito ou tema descontextualizado, com a formalidade que requer a profissão (relacionada ao curso de graduação do estudante) e isto é reforçado por meio de atividades de aprendizagem e com o uso da tecnologia como mediadora da aprendizagem para que, neste momento, o estudante possa abstrair o conceito. A avaliação das aprendizagens se faz presente desde o início dos processos de ensino e de aprendizagem (CAMARENA, 2017, p. 6).

Para atuar em consonância à didática da Matemática em Contexto, relativamente ao eixo da contextualização, o docente terá um papel de relevo antes da implementação do trabalho em sala de aula; deverá identificar situações com potencial para gerar eventos contextualizados, construir os eventos e elaborar os materiais didáticos que permitirão que os eventos possam ser desenvolvidos em sala de aula. Durante o trabalho dos estudantes com o evento, o professor, na maioria do tempo, assumirá o papel de mediador ou tutor da atividade, auxiliando os discentes a avançarem na resolução visada, mas sempre lhes propondo questionamentos como respostas às perguntas feitas por eles, ao invés de responde-las diretamente.

Em relação à atuação do professor no eixo da descontextualização, a última citação traz detalhes em algumas de suas linhas. Também a respeito desse eixo, com base em Camarena (2017), Lima, Bianchini e Gomes (2018) fazem os seguintes apontamentos acerca do trabalho do professor. Ao planejar atividades visando à descontextualização, além de, como já ressaltado, ser importante possibilitar ao estudante utilizar tecnologias, especialmente as digitais, para reforçar ou mediar a aprendizagem, é necessário que, por meio dessas atividades, os discentes possam: exercitar o trânsito por representações em diferentes registros do conceito a ser construído; considerar os distintos enfoques dos temas e conceitos matemáticos; estabelecer analogias com conhecimentos que já possui e vinculações com conhecimentos prévios necessários para a construção do conceito que está sendo estudado; superar obstáculos que porventura possui.

A questão da avaliação da aprendizagem neste primeiro bloco do MoDiMaCo, que, conforme evidencia a última citação, deve estar presente desde o início dos trabalhos com 
um determinado evento contextualizado, é detalhada por Camarena (2017): ao começar a trabalhar com determinada situação,

[..] diagnosticam-se conhecimentos prévios e obstáculos, sejam eles cognitivos, didáticos, contextuais, epistemológicos ou curriculares; isso permite a reflexão do aluno a respeito de sua situação atual em relação ao curso. [...] No desenvolvimento do processo, não são avaliadas apenas as aprendizagens, mas também os processos de desenvolvimento integral do estudante, como seu desenvolvimento na equipe, sua disposição para o trabalho em grupo, seu compromisso com as tarefas solicitadas. [...] Ao final do trabalho com determinado tema ou conceito, as aprendizagens dos estudantes são avaliadas por meio de atividades ou de eventos contextualizados planejados especialmente para esse fim. [...] Os instrumentos de avaliação podem ser um ou vários dos seguintes tipos: questionários, exercícios, elaboração de mapas conceituais, elaboração de uma síntese sobre o tema trabalhado, realização de um trabalho sobre a história dos conceitos, etc. (CAMARENA, 2017, p. 14).

No segundo bloco do MoDiMaCo, a ideia é, de acordo com Camarena (2013a), como um complemento para o trabalho em sala de aula com os eventos contextualizados, oferecer aos estudantes um curso extracurricular no qual possam ser realizadas atividades desenvolvendo:

- Habilidades de pensamento, tanto básicas (observação, identificação, comparação, classificação, hierarquização, associação, indução, dedução, síntese, memorização, etc.) quanto de ordem superior (criatividade, raciocínios lógico, crítico e analítico, a contextualização - transferir conhecimentos de uma área de conhecimento para outra, vinculando diferentes disciplinas -, a modelação matemática, a resolução de problemas, etc.).

- Habilidades metacognitivas: o estudante deve ter clareza a respeito do próprio conhecimento, se tem todos os elementos cognitivos para resolver um problema (e, particularmente, um evento contextualizado) ou se deve buscar auxílio em livros ou com outras pessoas; se questionar se o caminho adotado para resolver um problema parece adequado ou não, buscando contradições, incongruências ou outros elementos que lhe indiquem se a estratégia escolhida é boa ou não; verificar se a solução obtida é de fato coerente com o problema e se realmente o satisfaz, etc.

- Habilidades para aplicar heurísticas: ao resolver um problema (e especialmente um evento contextualizado) o estudante deve-se questionar: O que está sendo perguntado? Que tipo de dados tenho? Há fatores condicionantes? Quais são as variáveis no problema dado e quais são as constantes? Pode-se começar analisando um caso particular para depois resolver o problema de maneira genérica? Que analogias e semelhanças posso estabelecer com problemas já resolvidos? Posso pensar em propor esse problema de uma forma diferente por meio da qual possa ser mais fácil resolvê-lo? E outros.

Além de buscar, por meio desse curso extracurricular o desenvolvimento dessas habilidades mencionadas, objetiva-se também que ele permita o bloqueio de crenças negativas que possam atrapalhar o estudante no processo de resolução de problemas (e, claro, de eventos 
contextualizados). Camarena (2010; 2013a) não detalha que crenças são essas, mas compreendemos que se tratam, como destaca Blanco Nieto (2012) de crenças do estudante acerca da natureza da Matemática (que ela é para poucas pessoas que têm talento, é autoritária, baseada em regras em que predominam a memorização e os procedimentos algorítmicos, que ela se faz por meio de processos infalíveis e mecânicos, etc.) e crenças dos estudantes sobre si mesmos como aprendizes de Matemática (eu não sou capaz de resolver problemas, não tenho habilidade em Matemática, fico inseguro diante de um problema, é muito pouco provável que eu tenha êxito ao resolver um problema, ao me deparar com um problema sinto-me bloqueado, etc.).

Para Camarena (2013a), por meio de experiências de implementação desse tipo de curso, pelo menos durante um semestre, pôde-se perceber claramente reflexos nos resultados dos estudantes ao longo do processo formativo, tanto em termos de aproveitamento escolar, quanto de motivação para os estudos.

No terceiro bloco do MoDiMaCo, por sua vez, a ideia é realizar, nos últimos semestres do curso de graduação, o que na TMCC é denominado de Oficinas Interdisciplinares Abrangentes nas quais os estudantes possam resolver problemas reais apresentados por indústrias, empresas ou outros tipos de organizações nas quais o profissional que está sendo formado poderá atuar após sua graduação, ou seja, possam de fato se dedicar ao trabalho com eventos contextualizados verdadeiramente reais. Para Camarena (2013a, p. 30), essas oficinas constituem "o ponto culminante do processo didático de contextualização, de uma matemática social, entendida como uma matemática para o âmbito social" de uma determinada profissão. Nestas atividades, poderão ser efetivamente vistos os reflexos das ações fomentadas nos blocos anteriores visando capacitar os estudantes para transferir conhecimentos da Matemática para suas áreas de aplicação.

Para Camarena (2010; 2013a), uma particularidade desse terceiro bloco do MoDiMaCo é a necessidade, para sua implementação, da constituição de um grupo interdisciplinar de professores comprometidos para a realização das oficinas. Além disso, é interessante que estudantes ou até mesmo egressos de cursos de áreas afins àquele no qual as oficinas estão inseridas também possam participar da atividade, uma vez que, como os eventos contextualizados de fato reais são complexos e para enfrentar tal complexidade o trabalho em equipe é mais eficiente, a atuação com "pares de mesmas idades e linguagens e em quem confiam são componentes favoráveis à resolução dos eventos contextualizados" (CAMARENA, 2013a, p. 30).

Camarena $(2010 ; 2013 a)$ ressalta que, embora nessas Oficinas Interdisciplinares Abrangentes a formação integral e por competências dos estudantes seja ainda mais favorecida, o desenvolvimento de competências por parte dos estudantes é um dos objetivos centrais visados nos três blocos do MoDiMaCo. Passamos então, na sequência, a estabelecer relações entre esse Modelo Didático e os aspectos norteadores das atuais DCN salientados em uma das seções anteriores deste artigo e que, a seguir, serão melhor detalhados. 


\section{A consonância entre o MoDiMaCo e o que é preconizado nas atuais DCN}

Encerramos a segunda seção deste artigo destacando alguns aspectos norteadores presentes nas atuais Diretrizes Curriculares Nacionais, que, a nosso ver são aqueles mais diretamente possíveis de serem relacionados com MoDiMaCo. Tais aspectos, como evidenciamos por meio do Quadro 1, dizem respeito a diferentes dimensões a serem previstas nos Projetos Pedagógicos dos Cursos de Engenharia. Passamos então a detalhar de que maneira se faz menção a cada um deles nas DCN.

Quadro 1. Aspectos norteadores das atuais DCN que serão relacionados ao MoDiMaCo

\begin{tabular}{|c|c|}
\hline $\begin{array}{c}\text { O aspecto norteador diz } \\
\text { respeito a que dimensões dos } \\
\text { Projetos Pedagógicos dos } \\
\text { Cursos }\end{array}$ & Aspecto norteador \\
\hline $\begin{array}{l}\text { À concepção e ao perfil do } \\
\text { egresso }\end{array}$ & Valorização de um caráter social na formação do futuro engenheiro. \\
\hline À organização curricular & $\begin{array}{l}\text { Estabelecimento de um currículo por competências desenvolvidas ao } \\
\text { longo de todo o processo formativo. }\end{array}$ \\
\hline À recepção aos ingressantes & $\begin{array}{l}\text { Previsão de programas de acolhimento contemplando nivelamento de } \\
\text { conhecimentos, atendimento psicopedagógico, entre outros. }\end{array}$ \\
\hline \multirow{4}{*}{$\begin{array}{l}\text { Às estratégias de ensino e de } \\
\text { aprendizagem previstas }\end{array}$} & $\begin{array}{l}\text { Valorização de estratégias cujo foco sejam o desenvolvimento das } \\
\text { competências, tanto as de caráter geral quanto as de caráter específico } \\
\text { de determinada habilitação de Engenharia. }\end{array}$ \\
\hline & $\begin{array}{l}\text { Incentivo à adoção de estratégias de ensino e de aprendizagem que } \\
\text { valorizem a integração e a exploração dos conteúdos a partir de } \\
\text { situações-problema reais ou simulados da prática profissional. }\end{array}$ \\
\hline & Valorização de metodologias para aprendizagem ativas. \\
\hline & $\begin{array}{l}\text { Estímulo à utilização de tecnologias da informação, à aprendizagem } \\
\text { colaborativa, ao trabalho em equipe, à interdisciplinaridade e à } \\
\text { transdisciplinaridade. }\end{array}$ \\
\hline \multirow{2}{*}{$\begin{array}{l}\text { Aos papéis dos estudantes e dos } \\
\text { professores nos processos de } \\
\text { ensino e de aprendizagem }\end{array}$} & $\begin{array}{l}\text { Estudantes devem se tornar protagonistas na construção de seus } \\
\text { próprios conhecimentos. }\end{array}$ \\
\hline & O professor deve assumir o papel de mediador e tutor. \\
\hline \multirow[b]{2}{*}{ À avaliação da aprendizagem } & Avaliação contínua. \\
\hline & $\begin{array}{l}\text { Estímulo à utilização de instrumentos e estratégias de avaliação que } \\
\text { possibilitem a identificação de obstáculos e dos possíveis meios para } \\
\text { superá-los. }\end{array}$ \\
\hline À integração entre teoria e prátic & $\begin{array}{l}\text { Valorização de atividades de contextualização em parceria com } \\
\text { empresas e organizações. }\end{array}$ \\
\hline
\end{tabular}

Fonte: Dados da pesquisa.

Como princípio geral nas atuais DCN, decide-se que deve ser adotada uma visão sistêmica e holística na formação, não só em termos profissionais, mas também em relação ao cidadão-engenheiro, que deve ser conscientizado da importância de se comprometer com os valores fundamentais da sociedade em que está inserido. Nota-se, portanto, a valorização de um caráter social na formação a ser dada ao futuro engenheiro, formação essa a ser organizada não mais a partir de conteúdos que o profissional deverá dominar, mas sim de 
competências que deverá desenvolver ao longo da graduação. Ou seja, outro aspecto norteador para a construção das atuais DCN é o estabelecimento de um currículo por competências, sendo que estas (tanto as de caráter geral como as de caráter específico da habilitação de Engenharia cursada pelo estudante) deverão ser desenvolvidas ao longo de todo o processo formativo, "de modo que os estudantes não apenas acumulem conhecimentos, mas busquem, integrem, criem e produzam a partir de sua evolução no curso" (BRASIL, 2019a, p. 26).

Configura-se também como aspecto norteador das atuais DCN oportunizar, durante todo o processo formativo dos futuros engenheiros, a "inserção dos estudantes na construção de soluções para problemas que irão enfrentar na sua prática profissional" (BRASIL, 2019a, p. 26). Torna-se importante, portanto, na implementação da organização curricular dos cursos de Engenharia recorrer a estratégias de ensino e aprendizagem com foco "no desenvolvimento das competências, com a integração e exploração dos conteúdos a partir de situações-problema reais ou simulados da prática profissional". (Idem - grifos nossos). Essas estratégias, dentre as quais devem ser valorizadas as metodologias para aprendizagem ativas devem estar mais alinhadas à nova realidade global, especialmente no que diz respeito à utilização de tecnologias da informação, à aprendizagem colaborativa, à interdisciplinaridade e à transdisciplinaridade.

Deve ser privilegiada a construção pluridimensional da autonomia do estudante, de forma a contemplar o que, no Parecer CNE/CES No1/2019, é denominado de pilares do conhecimento: aprender a conhecer, aprender a fazer, aprender a conviver e aprender a ser. O trabalho em equipe deve ser estimulado e os estudantes é que devem se tornar protagonistas na construção de seus próprios conhecimentos. O professor deve assumir o papel de mediador e tutor.

Mais um aspecto norteador das atuais DCN que destacamos é a importância de os cursos de Engenharia implementarem atividades de contextualização em parceria com empresas e organizações, além das atividades de estágio. Segundo explicitado no Parecer CNE/CES $\mathrm{N}^{\mathrm{o}} 1 / 2019$, podem ser previstas ações "de docentes nas empresas, de profissionais das empresas no âmbito do curso, assim como maior direcionamento do projeto final de curso com vistas à resolução de problemas concretos, seja do setor produtivo, seja da sociedade em geral" (BRASIL, 2019a, p. 31).

Entendemos que orientar os processos de ensino e de aprendizagem de Matemática nos cursos de graduação em Engenharia por pressupostos deste Modelo Didático é uma forma de contribuir, também na abordagem de conceitos matemáticos, com o desenvolvimento de competências essenciais ao futuro profissional que está sendo formado. É, a nosso ver, uma possibilidade de, além de ressaltar a função da Matemática como ciência básica na formação do engenheiro, oportunizar que o desenvolvimento dos conteúdos matemáticos esteja vinculado ao objetivo do curso e ao perfil do egresso que se deseja formar, seja motivador aos estudantes e aconteça efetivamente de forma integrada tanto aos demais conteúdos básicos, quanto aos específicos e profissionalizantes das diferentes habilitações de Engenharia.

Postulamos que tal Modelo é potencialmente rico para, também na construção da base de conhecimentos matemáticos do futuro engenheiro, que na maioria das vezes, acaba ficando 
isolada nos chamados ciclos-básicos implementados nos dois primeiros anos dos cursos, desenvolver um trabalho intencionalmente voltado aos objetivos maiores que devem ser visados ao formar um engenheiro para a contemporaneidade. Mais do que isso, o MoDiMaCo, por meio da teoria que o fundamenta e a partir de seus procedimentos metodológicos, possibilita organizar minuciosamente uma abordagem da Matemática tendo essa finalidade em foco e de tal maneira que esteja articulada a diferentes dimensões das DCN, como evidenciamos por meio dos quadros que apresentaremos a seguir, nos quais destacamos o que é estabelecido em alguns artigos das Diretrizes (BRASIL, 2019b), selecionados por, em nosso ponto de vista, estarem mais diretamente relacionados aos objetivos desta investigação, e como o que é preconizado em tais artigos pode ser trabalhado por meio do MoDiMaCo.

A partir do Quadro 2, evidenciamos de que maneira os trabalhos propostos em diferentes blocos do MoDiMaCo podem contribuir em relação ao objetivo de formar um engenheiro que tenha as características que, de acordo com as atuais DCN, são as requeridas atualmente de um egresso. A análise do Quadro 2 mostra que dos seis incisos que compõem o Artigo $3^{\circ}$ das DCN, quatro (I, II, V e VI) trazem características do egresso que podem ser diretamente construídas por meio de trabalhos com os três blocos do MoDiMaCo; as presentes nos outros dois incisos (III e IV) são potencializadas nas resoluções de eventos contextualizados (no $1^{\circ}$ bloco) e de problemas reais (no $3^{\circ}$ bloco).

Quadro 2. Contribuições do MoDiMaCo relacionadas ao perfil do egresso explicitado nas atuais DCN

\begin{tabular}{|c|c|c|c|}
\hline $\begin{array}{l}\text { Dimensão } \\
\text { das DCN }\end{array}$ & \multicolumn{3}{|c|}{ Perfil do Egresso } \\
\hline $\begin{array}{c}\text { Artigo } \\
\text { das DCN }\end{array}$ & \multicolumn{3}{|c|}{$\begin{array}{l}\text { Art. } 3^{\circ} \mathrm{O} \text { perfil do egresso do curso de graduação em Engenharia deve compreender, entre } \\
\text { outras, as seguintes características: }\end{array}$} \\
\hline & O que é preconizado & $\begin{array}{c}\text { Bloco do } \\
\text { MoDiMaCo }\end{array}$ & $\begin{array}{c}\text { Como o MoDiMaCo pode } \\
\text { contribuir para garantir o que é } \\
\text { preconizado nas DCN? }\end{array}$ \\
\hline $\begin{array}{l}\text { I. ter visã } \\
\text { reflexivo, c } \\
\text { formação te } \\
\text { V. consid } \\
\text { econômico } \\
\text { segurança e } \\
\text { VI. atuar c } \\
\text { responsabil } \\
\text { sustentável }\end{array}$ & $\begin{array}{l}\text { holística e humanista, ser crítico, } \\
\text { ttivo, cooperativo e ético e com forte } \\
\text { hica; } \\
\text { ar os aspectos globais, políticos, } \\
\text { sociais, ambientais, culturais e de } \\
\text { aúde no trabalho. } \\
\text { isenção e comprometimento com a } \\
\text { ade social e com o desenvolvimento }\end{array}$ & $1^{\circ}, 2^{o}$ e $3^{o}$ & $\begin{array}{l}\text { O MoDiMaCo traz em seu bojo essa } \\
\text { ideia, uma vez que integra uma teoria } \\
\text { inserida na linha de investigação da } \\
\text { Matemática Social, na qual um dos } \\
\text { propósitos é possibilitar que o } \\
\text { estudante construa uma Matemática } \\
\text { para a vida e possa mover-se de forma } \\
\text { ética, crítica, criativa e analítica em } \\
\text { todos os âmbitos sociais (vida laboral, } \\
\text { profissional e diária). }\end{array}$ \\
\hline $\begin{array}{l}\text { II. estar ap } \\
\text { utilizar nov } \\
\text { empreende }\end{array}$ & $\begin{array}{l}\text { a pesquisar, desenvolver, adaptar e } \\
\text { tecnologias, com atuação inovadora e } \\
\text { ra. }\end{array}$ & $1^{\circ}, 2^{\circ}$ e $3^{o}$ & $\begin{array}{l}\text { Essas características podem ser } \\
\text { desenvolvidas por meio da resolução } \\
\text { de eventos contextualizados em sala de } \\
\text { aula }\left(1^{\circ} \text { bloco), nos cursos }\right. \\
\text { extracurriculares ( } 2^{\circ} \text { bloco) } \\
\text { especialmente ao resolver, nas oficinas }\end{array}$ \\
\hline
\end{tabular}




\begin{tabular}{|l|l|l|}
\hline & & $\begin{array}{l}\text { interdisciplinares abrangentes, } \\
\text { problemas reais da Engenharia. }\end{array}$ \\
\hline $\begin{array}{l}\text { III. ser capaz de reconhecer as necessidades dos } \\
\text { usuários, formular, analisar e resolver, de forma } \\
\text { criativa, os problemas de Engenharia. }\end{array}$ & $\begin{array}{l}\text { Essas características podem ser } \\
\text { desenvolvidas no trabalho com eventos } \\
\text { contextualizados em sala de aula ( } \\
\text { bloco) e ainda com maior intensidade } \\
\text { nas oficinas (3 bloco) ao resolver } \\
\text { problemas reais das indústrias, } \\
\text { empresas ou outras organizações em } \\
\text { que engenheiros atuam. }\end{array}$ \\
\hline $\begin{array}{l}\text { IV. adotar perspectivas multidisciplinares e } \\
\text { transdisciplinares em sua prática. }\end{array}$
\end{tabular}

Fonte: Dados da pesquisa.

No Quadro 3, explicitamos que contribuições uma abordagem da Matemática orientada pelos preceitos do MoDiMaCo pode trazer para o desenvolvimento das competências gerais que, conforme preconizam as atuais Diretrizes, no mundo contemporâneo, são esperadas de um engenheiro. Analisando o quadro, podemos perceber que dois oito incisos que compõem o Artigo $4^{\circ}$ das DCN, seis (I, II, III, IV, VI e VII) trazem competências gerais cujo desenvolvimento pode ser potencializado por meio das atividades realizadas nas esferas dos $1^{\circ}$ e $3^{\circ}$ blocos do MoDiMaCo. Competências elencadas em outros dois incisos (V e VIII), relacionadas à comunicação e à autonomia na aprendizagem, podem ter seu desenvolvimento diretamente estimulado também pelos cursos extracurriculares implementados no $2^{\circ}$ bloco do Modelo Didático em foco.

Quadro 3. Contribuições do MoDiMaCo relacionadas às competências gerais esperadas dos egressos, segundo as atuais DCN

\begin{tabular}{|c|c|c|c|}
\hline $\begin{array}{l}\text { Dimensão } \\
\text { das DCN }\end{array}$ & \multicolumn{3}{|c|}{ Competências Esperadas dos Egressos } \\
\hline $\begin{array}{c}\text { Artigo } \\
\text { das DCN }\end{array}$ & \multicolumn{3}{|c|}{$\begin{array}{l}\text { Art. } 4^{\mathbf{0}} \mathrm{O} \text { curso de graduação em Engenharia deve proporcionar aos seus egressos, ao } \\
\text { longo da formação, as seguintes competências gerais: } \\
\text { (e, obviamente, nota-se que, conforme o Parágrafo único deste artigo, além das } \\
\text { competências gerais, devem ser agregadas as competências específicas de acordo com a } \\
\text { habilitação ou com a ênfase do curso). }\end{array}$} \\
\hline & O que é preconizado & $\begin{array}{c}\text { Bloco do } \\
\text { MoDiMaCo }\end{array}$ & $\begin{array}{c}\text { Como o MoDiMaCo pode } \\
\text { contribuir para garantir o que é } \\
\text { preconizado nas DCN? }\end{array}$ \\
\hline \multicolumn{2}{|c|}{$\begin{array}{l}\text { I. formular e conceber soluções desejáveis de } \\
\text { engenharia, analisando e compreendendo os } \\
\text { usuários dessas soluções e seu contexto: } \\
\text { a) ser capaz de utilizar técnicas adequadas de } \\
\text { observação, compreensão, registro e análise das } \\
\text { necessidades dos usuários e de seus contextos } \\
\text { sociais, culturais, legais, ambientais e } \\
\text { econômicos; } \\
\text { b) formular, de maneira ampla e sistêmica, } \\
\text { questões de engenharia, considerando o usuário e } \\
\text { seu contexto, concebendo soluções criativas, bem } \\
\text { como o uso de técnicas adequadas. }\end{array}$} & $1^{\circ}$ e $3^{\circ}$ & $\begin{array}{l}\text { Essas características podem ser } \\
\text { desenvolvidas no trabalho com } \\
\text { eventos contextualizados em sala de } \\
\text { aula }\left(1^{\circ} \text { bloco) e ainda com maior }\right. \\
\left.\text { intensidade nas oficinas ( } 3^{\circ} \text { bloco }\right) \text { ao } \\
\text { resolver problemas reais das } \\
\text { indústrias, empresas ou outras } \\
\text { organizações em que engenheiros } \\
\text { atuam. }\end{array}$ \\
\hline
\end{tabular}


II. analisar e compreender os fenômenos físicos e químicos por meio de modelos simbólicos, físicos e outros, verificados e validados por experimentação:

a) ser capaz de modelar os fenômenos, os sistemas físicos e químicos, utilizando as ferramentas matemáticas, estatísticas, computacionais e de simulação, entre outras.

b) prever os resultados dos sistemas por meio dos modelos;

c) conceber experimentos que gerem resultados reais para o comportamento dos fenômenos e sistemas em estudo.

d) verificar e validar os modelos por meio de técnicas adequadas.

III. conceber, projetar e analisar sistemas, produtos (bens e serviços), componentes ou processos:

a) ser capaz de conceber e projetar soluções criativas, desejáveis e viáveis, técnica e economicamente, nos contextos em que serão aplicadas;

b) projetar e determinar os parâmetros construtivos e operacionais para as soluções de Engenharia;

c) aplicar conceitos de gestão para planejar, supervisionar, elaborar e coordenar projetos e serviços de Engenharia.

IV. implantar, supervisionar e controlar as soluções de Engenharia:

a) ser capaz de aplicar os conceitos de gestão para planejar, supervisionar, elaborar e coordenar a implantação das soluções de Engenharia.

b) estar apto a gerir, tanto a força de trabalho quanto os recursos físicos, no que diz respeito aos materiais e à informação;

c) desenvolver sensibilidade global nas organizações;

d) projetar e desenvolver novas estruturas empreendedoras e soluções inovadoras para os problemas;

e) realizar a avaliação crítico-reflexiva dos impactos das soluções de Engenharia nos contextos social, legal, econômico e ambiental.

V. comunicar-se eficazmente nas formas escrita, oral e gráfica:

a) ser capaz de expressar-se adequadamente, seja na língua pátria ou em idioma diferente do Português, inclusive por meio do uso consistente das tecnologias digitais de informação e comunicação (TDIC), mantendo-se sempre

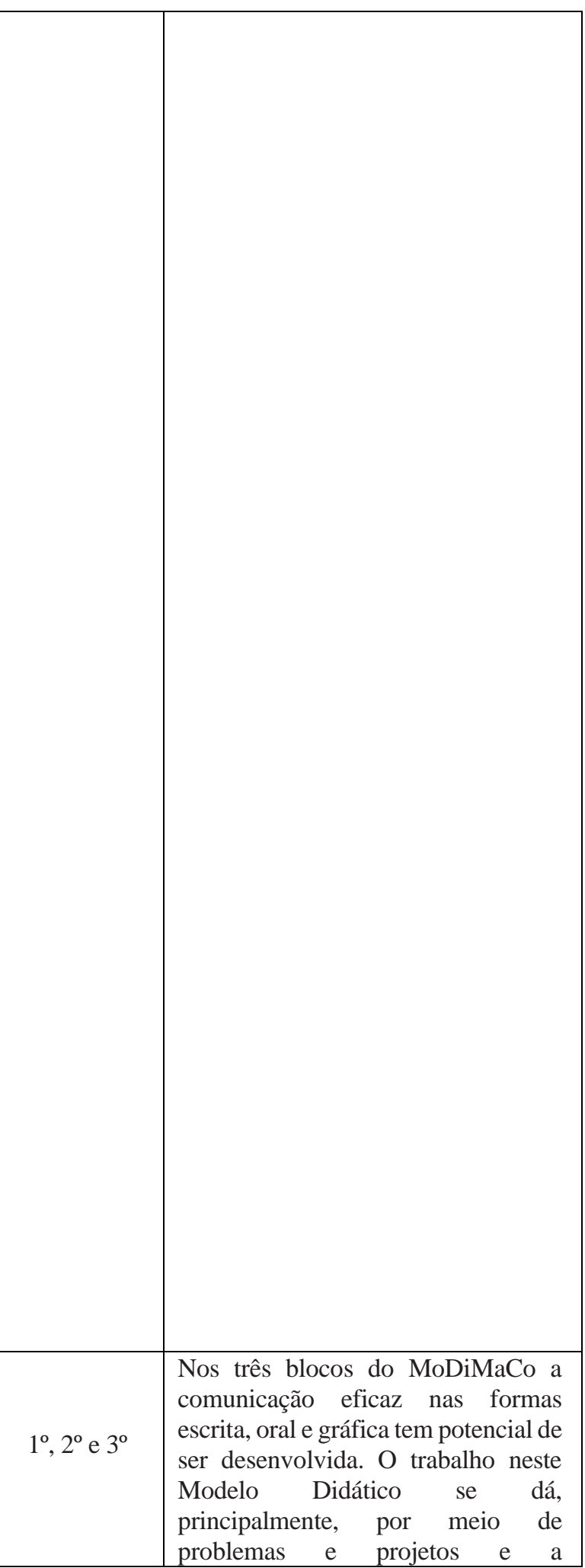




\begin{tabular}{|c|c|c|}
\hline $\begin{array}{l}\text { atualizado em termos de métodos e tecnologias } \\
\text { disponíveis. }\end{array}$ & & $\begin{array}{l}\text { comunicação é um aspecto } \\
\text { fundamental no processo de solução } \\
\text { de um problema ou no } \\
\text { desenvolvimento de um projeto e na } \\
\text { posterior análise e tradução da } \\
\text { solução encontrada para o contexto } \\
\text { da Engenharia. }\end{array}$ \\
\hline $\begin{array}{l}\text { VI. trabalhar e liderar equipes multidisciplinares: } \\
\text { a) ser capaz de interagir com as diferentes } \\
\text { culturas, mediante o trabalho em equipes } \\
\text { presenciais ou a distância, de modo que facilite a } \\
\text { construção coletiva; } \\
\text { b) atuar, de forma colaborativa, ética } \\
\text { profissional em equipes multidisciplinares, } \\
\text { tanto localmente quanto em rede; } \\
\text { c) gerenciar projetos e liderar, de forma proativa } \\
\text { e colaborativa, definindo as estratégias e } \\
\text { construindo o consenso nos grupos; } \\
\text { d) reconhecer e conviver com as diferenças } \\
\text { socioculturais nos mais diversos níveis em todos } \\
\text { os contextos em que atua (globais/locais); } \\
\text { e) preparar-se para liderar empreendimentos em } \\
\text { todos os seus aspectos de produção, de finanças, } \\
\text { de pessoal e de mercado. }\end{array}$ & $1^{\circ}$ e $3^{\circ}$ & $\begin{array}{l}\text { O desenvolvimento dessas } \\
\text { competências pode ser bastante } \\
\text { favorecido no } 1^{\circ} \text { bloco, uma vez que } \\
\text { o trabalho em sala de aula se dá por } \\
\text { meio de equipes de trabalho } \\
\text { colaborativo, sendo essas equipes } \\
\text { compostas por três tipos específicos } \\
\text { de lideranças que precisarão, o tempo } \\
\text { todo, exercê-las adequadamente. } \\
\text { No } 1^{\circ} \text { bloco, o trabalho se dá em } \\
\text { equipes disciplinares, mas no } 3^{\circ} \\
\text { bloco, são previstas equipes } \\
\text { compostas por estudantes de } \\
\text { diferentes áreas além da Matemática } \\
\text { e, portanto, o desenvolvimento da } \\
\text { competência explicitada na alínea (b) } \\
\text { é favorecida. }\end{array}$ \\
\hline $\begin{array}{l}\text { VII. conhecer e aplicar com ética a legislação e } \\
\text { os atos normativos no âmbito do exercício da } \\
\text { profissão: } \\
\text { a) ser capaz de compreender a legislação, a ética } \\
\text { e a responsabilidade profissional e avaliar os } \\
\text { impactos das atividades de Engenharia na } \\
\text { sociedade e no meio ambiente. } \\
\text { b) atuar sempre respeitando a legislação, e com } \\
\text { ética em todas as atividades, } \\
\text { zelando para que isto ocorra também no contexto } \\
\text { em que estiver atuando. }\end{array}$ & $1^{\mathrm{o}} \mathrm{e}$ & $\begin{array}{l}\text { O desenvolvimento dessas } \\
\text { competências é favorecido tanto no } \\
\text { trabalho comentos } \\
\text { contextualizados }\left(1^{\circ} \text { bloco) quanto na }\right. \\
\text { resolução de problemas reais }\left(3^{\circ}\right. \\
\text { bloco), uma vez que a formação } \\
\text { integral do estudante, com destaque } \\
\text { para o desenvolvimento de } \\
\text { competências fundamentais para um } \\
\text { cidadão e profissional de um mundo } \\
\text { globalizado, o que inclui questões } \\
\text { relacionadas à ética, é um dos } \\
\text { objetivos centrais da TMCC e, } \\
\text { consequentemente, do MoDiMaCo. }\end{array}$ \\
\hline $\begin{array}{l}\text { VIII. aprender de forma autônoma e lidar com } \\
\text { situações e contextos complexos, atualizando-se } \\
\text { em relação aos avanços da ciência, da tecnologia } \\
\text { e aos desafios da inovação: } \\
\text { a) ser capaz de assumir atitude investigativa e } \\
\text { autônoma, com vistas à aprendizagem contínua, } \\
\text { à produção de novos conhecimentos e ao } \\
\text { desenvolvimento de novas tecnologias. } \\
\text { b) aprender a aprender. }\end{array}$ & $1^{\mathrm{o}}, 2^{\mathrm{o}}$ e $3^{\mathrm{o}}$ & $\begin{array}{l}\text { O desenvolvimento dessas } \\
\text { competências é diretamente } \\
\text { potencializado pelos trabalhos com } \\
\text { eventos contextualizados (no } 1^{\circ} \\
\text { bloco) e com problemas reais } \\
\text { propostos por organizações nas quais } \\
\text { possam atuar um engenheiro (no } 3^{\circ} \\
\text { bloco). } \\
\text { Nos cursos extracurriculares }\left(2^{\circ}\right. \\
\text { bloco), em nosso ponto de vista, o } \\
\text { desenvolvimento de habilidades } \\
\text { (metacognitivas, de pensamento, de }\end{array}$ \\
\hline
\end{tabular}




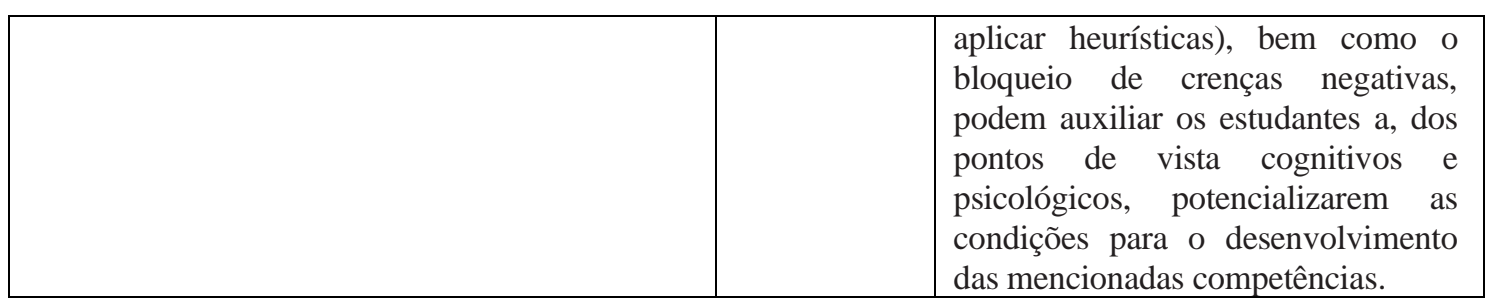

Fonte: Dados da pesquisa

Pelo exposto no Quadro 4, evidenciamos de que maneira os preceitos do MoDiMaCo se revelam como potenciais contribuições na organização de atividades de aprendizagem que possam assegurar o desenvolvimento das competências esperadas dos egressos. Demos destaque nesse quadro a alguns dos parágrafos do inciso VIII do Art. $6^{\circ}$ das DCN. Dos nove parágrafos evidenciados, quatro contemplam aspectos que podem ser potencializados nos $1^{\circ} \mathrm{e}$ $3^{\circ}$ blocos do Modelo Didático em tela $\left(\S 2^{\circ}, \S 4^{\circ}, \S 7^{\circ}\right.$ e $\left.\S 8^{\circ}\right)$, três nos $1^{\circ}, 2^{\circ}$ e $3^{\circ}$ blocos $\left(\S 3^{\circ}, \S 5^{\circ}\right.$ e $\left.\S 6^{\circ}\right)$ e dois no $3^{\circ}$ bloco $\left(\S 9^{\circ}\right.$ e $\left.\S 10\right)$.

Quadro 4. Contribuições do MoDiMaCo relacionadas à organização das atividades de aprendizagem visando o desenvolvimento das competências esperadas do egresso

\begin{tabular}{|c|c|c|c|}
\hline $\begin{array}{l}\text { Dimensão } \\
\text { das DCN }\end{array}$ & \multicolumn{3}{|c|}{$\begin{array}{l}\text { Organização do curso - o conjunto das atividades de aprendizagem de forma a assegurar o } \\
\text { desenvolvimento das competências esperadas do egresso }\end{array}$} \\
\hline & \multicolumn{3}{|c|}{$\begin{array}{l}\text { Art. } 6^{\circ} \text { O curso de graduação em Engenharia deve possuir Projeto Pedagógico do Curso } \\
\text { (PPC) que contemple o conjunto das atividades de aprendizagem e assegure o } \\
\text { desenvolvimento das competências, estabelecidas no perfil do egresso. Os projetos } \\
\text { pedagógicos dos cursos de graduação em Engenharia devem especificar e descrever } \\
\text { claramente: } \\
\text { (Vamos destacar aqui o inciso VIII, cujo enunciado é: o processo de autoavaliação e gestão } \\
\text { de aprendizagem do curso que contemple os instrumentos de avaliação das competências } \\
\text { desenvolvidas, e respectivos conteúdos, o processo de diagnóstico e a elaboração dos } \\
\text { planos de ação para a melhoria da aprendizagem, especificando as responsabilidades e a } \\
\text { governança do processo). }\end{array}$} \\
\hline & O que é preconizado & & $\begin{array}{c}\text { Como o MoDiMaCo pode } \\
\text { contribuir para garantir o que é } \\
\text { preconizado nas DCN? }\end{array}$ \\
\hline \multicolumn{2}{|c|}{$\begin{array}{l}\text { VIII. } \\
\$ \mathbf{2}^{\mathbf{0}} \text { Deve-se estimular as atividades que } \\
\text { articulem simultaneamente a teoria, a prática e o } \\
\text { contexto de aplicação, necessárias para o } \\
\text { desenvolvimento das competências, } \\
\text { estabelecidas no perfil do egresso, incluindo as } \\
\text { ações de extensão e a integração empresa-escola. } \\
\$ \mathbf{4}^{\mathbf{0}} \text { Devem ser implementadas, desde o início do } \\
\text { curso, as atividades que promovam a integração } \\
\text { e a interdisciplinaridade, de modo coerente com } \\
\text { o eixo de desenvolvimento curricular, para } \\
\text { integrar as dimensões técnicas, científicas, } \\
\text { econômicas, sociais, ambientais e éticas. } \\
\$ \mathbf{7}^{\mathbf{0}} \text { Devem ser implementadas as atividades } \\
\text { acadêmicas de síntese dos conteúdos, de }\end{array}$} & $1^{\circ}$ e $3^{\circ}$ & $\begin{array}{l}\text { A ideia central presente nos } 1^{\circ} \text { e } 3^{\circ} \\
\text { blocos é a contextualização da } \\
\text { Matemática por meio de problemas e } \\
\text { projetos trabalhados pelos estudantes } \\
\text { em equipes colaborativas e, desta } \\
\text { forma, consequentemente os aspectos } \\
\text { mencionados são contemplados. No } \\
1^{\circ} \text { bloco a contextualização se dá a } \\
\text { partir dos conteúdos não matemáticos } \\
\text { que compõem o currículo ou de } \\
\text { situações do cotidiano profissional de } \\
\text { um egresso da habilitação de } \\
\text { Engenharia em questão. E no } 3^{\circ} \\
\text { bloco, a contextualização é efetivada } \\
\text { a partir de situações reais trazidas por }\end{array}$ \\
\hline
\end{tabular}




\begin{tabular}{|c|c|c|}
\hline $\begin{array}{l}\text { integração dos conhecimentos e de articulação de } \\
\text { competências. } \\
\S \mathbf{8}^{\mathbf{0}} \text { Devem ser estimuladas as atividades } \\
\text { acadêmicas, tais como trabalhos de iniciação } \\
\text { científica, competições acadêmicas, projetos } \\
\text { interdisciplinares e transdisciplinares, projetos de } \\
\text { extensão, atividades de voluntariado, visitas } \\
\text { técnicas, trabalhos em equipe, desenvolvimento } \\
\text { de protótipos, monitorias, participação em } \\
\text { empresas juniores, incubadoras e outras } \\
\text { atividades empreendedoras. }\end{array}$ & & $\begin{array}{l}\text { organizações nas quais os } \\
\text { engenheiros podem atuar. }\end{array}$ \\
\hline $\begin{array}{l}\text { VIII. } \\
\$ \mathbf{3}^{\mathbf{0}} \text { Devem ser incentivados os trabalhos dos } \\
\text { discentes, tanto individuais quanto em grupo, sob } \\
\text { a efetiva orientação docente. } \\
\$ \mathbf{6}^{\mathbf{0}} \text { Deve ser estimulado o uso de metodologias } \\
\text { para aprendizagem ativa, como forma de } \\
\text { promover uma educação mais centrada no aluno. }\end{array}$ & $1^{o}, 2^{o}$ e $3^{o}$ & $\begin{array}{l}\text { Nos três blocos do MoDiMaCo a } \\
\text { ideia é que o estudante seja o } \\
\text { protagonista na construção de seu } \\
\text { próprio conhecimento, ou seja, o } \\
\text { processo de aprendizagem é centrado } \\
\text { no discente. O professor assume o } \\
\text { papel de mediador, tendo } \\
\text { protagonismo efetivo no } \\
\text { planejamento das atividades de } \\
\text { ensino a ser implementadas. }\end{array}$ \\
\hline $\begin{array}{l}\text { VIII. } \\
\$ \mathbf{5}^{\mathbf{0}} \text { Os planos de atividades dos diversos } \\
\text { componentes curriculares do curso, } \\
\text { especialmente em seus objetivos, devem } \\
\text { contribuir para a adequada formação do } \\
\text { graduando em face do perfil estabelecido do } \\
\text { egresso, relacionando-os às competências } \\
\text { definidas. }\end{array}$ & $1^{\circ}, 2$ & $\begin{array}{l}\text { Entendemos que orientar o ensino da } \\
\text { Matemática a partir dos preceitos do } \\
\text { MoDiMaCo, considerando seus três } \\
\text { blocos, é uma maneira de, na } \\
\text { abordagem desse componente } \\
\text { curricular, também para o } \\
\text { desenvolvimento do perfil do egresso } \\
\text { desejado e das competências dele } \\
\text { esperadas. }\end{array}$ \\
\hline $\begin{array}{l}\text { VIII. } \\
\text { § } \mathbf{9}^{\mathbf{0}} \text { É recomendável que as atividades sejam } \\
\text { organizadas de modo que aproxime os estudantes } \\
\text { do ambiente profissional, criando formas de } \\
\text { interação entre a instituição e o campo de atuação } \\
\text { dos egressos. } \\
\$ \mathbf{1 0} \text { Recomenda-se a promoção frequente de } \\
\text { fóruns com a participação de profissionais, } \\
\text { empresas e outras organizações públicas e } \\
\text { privadas, a fim de que contribuam nos debates } \\
\text { sobre as demandas sociais, humanas e } \\
\text { tecnológicas para acompanhar a evolução } \\
\text { constante da Engenharia, para melhor definição e } \\
\text { atualização do perfil do egresso. }\end{array}$ & $3^{\circ}$ & $\begin{array}{l}\text { Embora a aproximação com questões } \\
\text { do ambiente profissional ocorra } \\
\text { também por meio da resolução de } \\
\text { eventos contextualizados no } 1^{\circ} \text { bloco, } \\
\text { entendemos que é no } 3^{\circ} \text { bloco, no } \\
\text { momento em que os estudantes, em } \\
\text { Oficinas Interdisciplinares } \\
\text { Abrangentes, resolvem problemas } \\
\text { reais trazidos por organizações em } \\
\text { que engenheiros atuam, é que os } \\
\text { aspectos destacados podem ser } \\
\text { implementados de forma mais } \\
\text { específica e direta. }\end{array}$ \\
\hline
\end{tabular}

Fonte: Dados da pesquisa

Outro aspecto que norteia as atuais Diretrizes é a necessidade de as IES, uma vez que recebem estudantes com perfil muito heterogêneo, tanto em termos culturais quanto de conhecimentos prévios, implementarem programas de acolhimento para os ingressantes que “devem contemplar o nivelamento de conhecimentos, o atendimento psicopedagógico, além 
de outros, que possam influir no desempenho dos estudantes no curso. Esse acompanhamento e apoio aos estudantes podem contribuir, de maneira decisiva, para o combate a grande evasão verificada nos cursos de Engenharia” (BRASIL, 2019a, p. 34).

A partir do Quadro 5, no qual destacamos o Artigo $7^{\circ}$ das DCN, é possível identificar que o $1^{\circ}$ e o $2^{\circ}$ blocos do MoDiMaCo também podem contribuir, de maneira significativa, na implementação de programas de acolhimento dos ingressantes nos cursos de Engenharia, especialmente no que diz respeito ao nivelamento em termos de conhecimentos matemáticos prévios da Educação Básica que são essenciais para o ensino superior; ao desenvolvimento de habilidades fundamentais para a resolução de problemas (da Engenharia e das ciências que lhe são básicas) e ao bloqueio de crenças negativas que porventura os estudantes tenham a respeito da Matemática e de si mesmos como aprendizes dos conteúdos desta área, que poderão os atrapalhar no enfrentamento dos problemas com os quais irão se deparar no curso e, talvez, ocasionar evasões e reprovações.

Quadro 5. Contribuições do MoDiMaCo relacionadas à organização e implementação de sistemas de acolhimento e nivelamento, visando diminuir a retenção e a evasão

\begin{tabular}{|c|c|c|c|}
\hline $\begin{array}{l}\text { Dimensão } \\
\text { das DCN }\end{array}$ & \multicolumn{3}{|c|}{$\begin{array}{l}\text { Organização do curso - implementação de sistemas de acolhimento e nivelamento, visando } \\
\text { à diminuição da retenção e da evasão. }\end{array}$} \\
\hline $\begin{array}{c}\text { Artigo } \\
\text { das DCN }\end{array}$ & \multicolumn{3}{|c|}{$\begin{array}{c}\text { Art. } 7^{\mathbf{0}} \text { Com base no perfil dos seus ingressantes, o Projeto Pedagógico do Curso (PPC) } \\
\text { deve prever os sistemas de acolhimento e nivelamento, visando à diminuição da retenção e } \\
\text { da evasão, ao considerar: }\end{array}$} \\
\hline & O que é preconizado & $\begin{array}{c}\text { Bloco do } \\
\text { MoDiMaCo }\end{array}$ & $\begin{array}{l}\text { Como o MoDiMaCo pode } \\
\text { contribuir para garantir o que é } \\
\text { preconizado nas DCN? }\end{array}$ \\
\hline \multicolumn{2}{|c|}{$\begin{array}{l}\text { I. as necessidades de conhecimentos básicos que } \\
\text { são pré-requisitos para o ingresso nas atividades } \\
\text { do curso de graduação em Engenharia. }\end{array}$} & $1^{\mathrm{o}}$ & $\begin{array}{l}\text { Entendemos que no } 1^{\circ} \text { bloco o } \\
\text { docente pode planejar eventos } \\
\text { contextualizados visando retomar os } \\
\text { conhecimentos matemáticos básicos } \\
\text { que são pré-requisitos para a } \\
\text { aprendizagem em cursos de } \\
\text { Engenharia, mas já de forma } \\
\text { vinculada aos objetivos do ensino } \\
\text { superior e aos problemas das futuras } \\
\text { áreas de atuações profissionais dos } \\
\text { estudantes, e não como uma simples } \\
\text { revisão do que foi abordado na } \\
\text { Educação Básica. }\end{array}$ \\
\hline \multicolumn{2}{|c|}{$\begin{array}{l}\text { II. a preparação pedagógica e psicopedagógica } \\
\text { para o acompanhamento das atividades do curso } \\
\text { de graduação em Engenharia. } \\
\text { III. a orientação para o ingressante, visando } \\
\text { melhorar as suas condições de permanência no } \\
\text { ambiente da educação superior. }\end{array}$} & $2^{\circ}$ & $\begin{array}{l}\text { Em nossa visão, nos cursos } \\
\text { extracurriculares do } 2^{\circ} \text { bloco, o } \\
\text { desenvolvimento de habilidades } \\
\text { (metacognitivas, de pensamento e } \\
\text { para aplicar heurísticas) e o bloqueio } \\
\text { de crenças negativas (tanto em } \\
\text { relação à Matemática, quanto em } \\
\text { relação à maneira como o aluno se } \\
\text { percebe como aprendiz desta ciência) } \\
\text { podem possibilitar, também por meio } \\
\text { da Matemática, contribuir de maneira }\end{array}$ \\
\hline
\end{tabular}




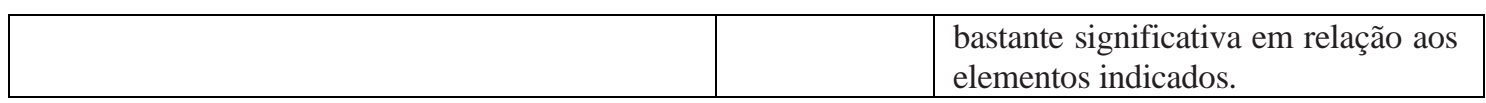

Fonte: Dados da pesquisa

Conforme preconizam as atuais DCN, a avaliação da aprendizagem deve ser contínua e por meio de instrumentos e estratégias que possibilitem a identificação de obstáculos e dos possíveis meios para superá-los. E, no que diz respeito ao processo avaliação das atividades realizadas pelos estudantes durante o curso e, consequentemente das competências que devem ser desenvolvidas, salientamos as contribuições trazidas a este processo pelo $1^{\circ}$ bloco do MoDiMaCo, no qual os procedimentos avaliativos estão plenamente alinhados ao que é preconizado nas DCN, especialmente no que consta no Artigo 13, como evidenciamos no Quadro 6.

Quadro 6. Contribuições do MoDiMaCo relacionadas à avaliação das atividades desenvolvidas pelos estudantes

\begin{tabular}{|c|c|c|}
\hline \multicolumn{3}{|c|}{ Avaliação das atividades desenvolvidas pelos estudantes } \\
\hline \multicolumn{3}{|c|}{$\begin{array}{l}\text { Art. 13. A avaliação dos estudantes deve ser organizada como um reforço, em relação ao } \\
\text { aprendizado e ao desenvolvimento das competências: }\end{array}$} \\
\hline O que é preconizado & $\begin{array}{c}\text { Bloco do } \\
\text { MoDiMaCo }\end{array}$ & $\begin{array}{c}\text { Como o MoDiMaCo pode } \\
\text { contribuir para garantir o que é } \\
\text { preconizado nas DCN? }\end{array}$ \\
\hline $\begin{array}{l}\S \mathbf{1}^{\mathbf{0}} \text { As avaliações da aprendizagem e das } \\
\text { competências devem ser contínuas e previstas } \\
\text { como parte indissociável das atividades } \\
\text { acadêmicas. } \\
\$ \mathbf{2}^{\mathbf{0}} \text { O processo avaliativo deve ser diversificado } \\
\text { e adequado às etapas e às atividades do curso, } \\
\text { distinguindo o desempenho em atividades } \\
\text { teóricas, práticas, laboratoriais, de pesquisa e } \\
\text { extensão. } \\
\$ \mathbf{3}^{\circ} \text { O processo avaliativo pode dar-se sob a } \\
\text { forma de monografias, exercícios ou provas } \\
\text { dissertativas, apresentação de seminários e } \\
\text { trabalhos orais, relatórios, projetos e atividades } \\
\text { práticas, entre outros, que demonstrem o } \\
\text { aprendizado e estimulem a produção intelectual } \\
\text { dos estudantes, de forma individual ou em equipe. }\end{array}$ & $1^{\mathrm{o}}$ & $\begin{array}{l}\text { O processo de avaliação no } 1^{\circ} \text { bloco } \\
\text { do MoDiMaCo é totalmente alinhado } \\
\text { às ideias preconizada nesses } \\
\text { parágrafos. A avaliação é contínua, } \\
\text { desde o início do processo e é } \\
\text { realizada com o objetivo de } \\
\text { diagnosticar conhecimentos prévios, } \\
\text { identificar obstáculos para superá-los } \\
\text { e avaliar não somente as } \\
\text { aprendizagens, o mas } \\
\text { desenvolvimento integral do } \\
\text { estudante (e consequentemente as } \\
\text { competências por ele desenvolvidas). } \\
\text { Além disso, é realizada a partir de } \\
\text { diferentes instrumentos: exercícios, } \\
\text { questionários, elaboração de mapas } \\
\text { conceituais, elaboração de uma } \\
\text { síntese sobre o tema trabalhado, } \\
\text { realização de um trabalho sobre a } \\
\text { história dos conceitos, etc. }\end{array}$ \\
\hline
\end{tabular}

Fonte: Dados da pesquisa

Tendo cumprido nossa proposta inicial de refletir acerca das possibilidades trazidas pelo MoDiMaCo para uma abordagem da Matemática na Engenharia, de maneira consonantes às atuais Diretrizes Curriculares para estes cursos de graduação, na próxima seção apresentamos algumas considerações que depreendem do estudo que realizamos. 


\section{Considerações finais}

Neste artigo apresentamos os resultados de um estudo que, do ponto de vista metodológico, associou aspectos da pesquisa documental e da pesquisa bibliográfica, por meio do qual buscamos refletir e destacar as potencialidades do Modelo Didático da Matemática em Contexto, desenvolvido no âmbito da Teoria A Matemática no Contexto das Ciências, para conduzir, nas graduações em diferentes habilitações de Engenharia, uma abordagem dos conteúdos matemáticos de forma harmônica àquilo que é estabelecido por meio das atuais Diretrizes Curriculares Nacionais para esses cursos.

Identificamos contribuições do referido Modelo Didático relacionadas a diferentes dimensões das Diretrizes: ao perfil do egresso desejado (sendo que os três blocos do MoDiMaCo têm potencial de contribuir significativamente no alcance desse perfil); às competências gerais esperadas dos egressos (e nesta dimensão as contribuições mais efetivas são por meio das atividades vinculadas ao $1^{\circ}$ e o $3^{\circ}$ bloco do Modelo, embora às do $2^{\circ}$ bloco também contribuam); às atividades de aprendizagem visando o desenvolvimento das competências esperadas de um egresso (e novamente evidenciou-se um destaque para o $1^{\circ} \mathrm{e}$ o $3^{\circ}$ bloco, mas havendo, ainda que em menor medida também contribuições relacionadas ao $2^{\circ}$ bloco); à implantação de sistemas de acolhimento e nivelamento visando contribuir para a diminuição da retenção e da evasão (e nessa dimensão as contribuições estão nas atividades do $1^{\circ} \mathrm{e}$, sobretudo, do $2^{\circ}$ bloco); e à avaliação das atividades desenvolvidas pelos estudantes (especificamente nas atividades do $1^{\circ}$ bloco do MoDiMaCo).

Embora a configuração de um currículo por disciplinas não seja a mais apropriada para o desenvolvimento das competências esperadas de um profissional que irá atuar na contemporaneidade, sabemos que abrir mão de uma organização disciplinar ainda é complicado para muitas Instituições de Ensino Superior. E, neste sentido, evidenciamos mais uma contribuição do MoDiMaCo: permitir uma abordagem interdisciplinar ou multidisciplinar da Matemática mesmo em um currículo composto por disciplinas. O Modelo Didático em questão prevê como objetivo principal para o ensino de Matemática o desenvolvimento de competências profissionais, laborais e para a vida e uma abordagem desta ciência de maneira vinculada às situações com as quais os futuros engenheiros irão enfrentar em seus cotidianos profissionais, mas sem exigir, como premissa para alcançar esse objetivo, uma organização não disciplinar do currículo. O que deve ser modificado, segundo os preceitos deste Modelo, é a maneira com que os conteúdos matemáticos são trabalhos nas disciplinas destinadas a eles.

Convém salientar que muitos dos aspectos do MoDiMaCo por nós iluminados neste artigo, guardam estreita relação com características que, de acordo com Graham (2018), estão relacionadas ao que se espera do setor da Educação em Engenharia no futuro e que, portanto, irão diferenciar instituições chamadas atualmente de líderes emergentes das que hoje em dia são as líderes no setor. Tais características são: (i) a necessidade de uma inflexão rumo a um currículo de Engenharia que seja socialmente relevante; (ii) a necessidade de possibilitar ao estudante experiências curriculares distintas e centradas no estudante no âmbito de uma 
abordagem educacional integrada e identificada; (iii) programas com abordagens multidisciplinares; (iv) oferecer aos estudantes caminhos para a contextualização e a aplicação de conhecimentos construídos e habilidades desenvolvidas por meio das diferentes componentes curriculares do curso; (v) permitir a vivência, por parte dos estudantes, de momentos de identificação e solução de problemas por meio de trabalhos em equipes; (vi) possibilitar, ao longo das atividades do curso, o desenvolvimento da responsabilidade social do futuro engenheiro e de suas capacidades empresariais; e (vii) prever, ao longo do curso, uma parceira estreita entre a universidade e, consequentemente, os estudantes, e a indústria.

Embora a TMCC e, consequentemente seu Modelo Didático, tenha sido desenvolvida originalmente para o trabalho com a Matemática em cursos de Engenharia, essa Teoria e seu Modelo podem também ser estendidos para o trabalho com outras ciências básicas, como a Física, a Química, a Biologia, etc. Esse referencial teórico originário da extensão da TMCC recebe o nome de Ciências em Contexto, conforme discute Camarena (2018). Entendemos como essencial uma reorientação, na formação do futuro engenheiro, não somente da abordagem da Matemática, mas de todas as ciências básicas, uma vez que, conforme destaca Graham (2018, p. 37), um dos desafios a serem vencidos para o progresso do setor da Educação em Engenharia é exatamente "a dificuldade em reformular disciplinas fundamentais que são frequentemente ofertadas pelas escolas de ciências da universidade e garantir que suas abordagens, conteúdos e focos constituam uma parte coerente e consistente do programa de graduação em engenharia como um todo". Essa reorientação deve ser, como evidenciado por meio dos procedimentos metodológicos do MoDiMaCo por nós discutidos neste artigo, no sentido de integrar as disciplinas de ciências básicas e as demais que compõem o currículo, uma vez que para Graham (2018, p. 37), o desenvolvimento da Educação em Engenharia é limitado "pela separação estrutural que muitas vezes existe entre e além das disciplinas da engenharia, pela falta de interação (entre elas) principalmente no ensino e na aprendizagem".

Como discutimos em Lima et al. (2019), para a implementação de modelos didáticos como o MoDiMaCo, um primeiro passo é o estabelecimento de diálogos entre os professores universitários que lecionam ciências básicas e aqueles de outras áreas presentes nos cursos. Este possibilitará a identificação de situações de diferentes habilitações da Engenharia que requerem a mobilização de conhecimentos das ciências básicas para suas abordagens e que poderão servir como ponto de partida para a construção dos eventos contextualizados que, no Modelo discutido são as principais ferramentas para um trabalho interdisciplinar com essas ciências.

Outra questão a ser considerada de forma a viabilizar que modelos como o MoDiMaCo possam chegar efetivamente aos cursos de Engenharia é a necessidade de estruturar formações continuadas para professores que lecionam disciplinas de ciências básicas nessas graduações. Por meio da fase docente da TMCC, estabelecem-se, inclusive, conforme ressalta Camarena (2013b), os elementos cognitivos mínimos que devem possuir um programa de formação e atualização para tais professores. Esses elementos dizem respeito a quatro categorias: (i) conhecimentos dos conteúdos a serem ensinados; (ii) conhecimento acerca dos processos de ensino e de aprendizagem; (iii) conhecimentos sobre as habilitações 
de Engenharia em que os docentes atuam; e (iv) conhecimento sobre o uso de tecnologias digitais de informação e de comunicação como mediadoras da aprendizagem do estudante. Atrelados à implementação das novas DCN, entendemos que, necessariamente, as IES devem colocar em ação programas de formação para seus docentes. Afinal, de nada adiantam Diretrizes com pressupostos inovadores se, em sala de aula, elas se traduzirem em práticas já consagradas, mas totalmente em dissonância a esses pressupostos e aos novos objetivos visados.

Finalizamos esse artigo fazendo referência a uma ideia apresentada por Graham (2018), com a qual concordamos: o ensino de Engenharia tem um papel fundamental no enfrentamento dos principais desafios postos às universidades no século XXI, podendo ser tanto o catalizador, quanto a incubadora para o desenvolvimento e difusão de melhores práticas. Esperamos que as reflexões por nós apresentadas nesse texto possam contribuir neste sentido.

\section{Notas:}

1. As reflexões apresentadas neste artigo são aprofundamentos daquelas que desencadeamos no trabalho $\mathrm{O}$ Modelo Didático da Matemática em Contexto como possibilidade para um ensino de Matemática consonante às novas Diretrizes Curriculares Nacionais, que foi apresentado em setembro de 2019 no XLVII Congresso Brasileiro de Educação em Engenharia (COBENGE) e cujo texto completo é citado neste artigo como Lima et al. (2019).

\section{Referências}

BIANCHINI, B. L. et al. Competências matemáticas: perspectivas da SEFI e da MCC. Educação Matemática Pesquisa, v.19, n.1, p. 49-79, 2017. DOI: http://dx.doi.org/10.23925/1983-3156.2017v19i1p49-79

BLANCO NIETO, L. J. Influencias del domínio afectivo en la enseñanza y el aprendizaje de las matemáticas. In: PLANAS, N. (Coord.). Teoría, crítica y práctica de la educación matemática. Barcelona/Espanha: Editorial GRAÓ, p. 171-186, 2012.

BRASIL. Ministério da Educação. Parecer CNE/CES n. 1/2019, de 23 de abril de 2019. Dispõe sobre as Diretrizes Curriculares Nacionais do Curso de Graduação em Engenharia, 2019a. Disponível em: <http://portal.mec.gov.br/docman/marco-2019-pdf/109871-pces001-19-1/file〉. Acesso em: 06 mai. 2020.

BRASIL. Ministério da Educação. Resolução CNE/CES n. 2/2019, de 23 de abril de 2019. Institui as Diretrizes Curriculares Nacionais do Curso de Graduação em Engenharia, 2019b. Disponível em: < http://www.in.gov.br/web/dou/-/resolu\%C3\%87\%C3\%83o-n\%C2\%BA-2-de-24-de-abril-de-201985344528>. Acesso em: 06 mai. 2020.

CAMARENA, P. El currículo de las matemáticas en ingeniería. Memorias de las Mesas redondas sobre definición de líneas de investigación en el IPN, México, 1984.

CAMARENA, P. Reporte de proyecto de investigación titulado: El problema cognitivo de las funciones generalizadas y sus transformadas de Fourier y Laplace, con no. de registro DEPI-IPN: 953737, desarrollado de 1995 a 1998. Editorial ESIME-IPN, México, 1995.

CAMARENA, P. Reporte de proyecto de investigación titulado: Etapas de la matemática en el contexto de la ingeniería, con no. de registro: CGPI-IPN: 990413. Editorial ESIME-IPN, México, 1999. 
CAMARENA, P. Aportaciones de Investigación al Aprendizaje y Enseñanza de la Matemática en Ingeniería, $\quad 2010 . \quad$ Disponível em: <http://www.ai.org.mx/ai/archivos/ingresos/camarenagallardo/dra._patricia_camarena_gallardo.pdf> Acesso em 02 de jun. de 2020.

CAMARENA, P. Concepción de competencias de las ciencias básicas em el nível universitário. In: DIPP, A.J., MACÍAS, A. B. (Org.). Competencias y Educación - miradas múltiples de una relación. México: Instituto Universitario Anglo Español A.C e Red Durango de Investigadores Educativos A.C. p.88-118, 2011.

CAMARENA, P. A treinta años de la teoría educativa "Matemática en el contexto de las ciencias", Revista Innovación Educativa, Vol. 13, Núm. 62, p.17-44, 2013.

CAMARENA, P. El conocimiento de las ciências básicas en profesores de ingeniería . In: CARRILLO, A.J., ONTIVEROS, H. V., CECEÑA, T. P. (Eds.). Formación docente: Un análisis desde la práctica. México: Red Durango de Investigadores Educativos A.C. p. 212-249, 2013 b.

CAMARENA, P. La Matemática Social en el Desarrollo Integral del Alumno. Innovación Educativa, v.14, n.65, p. 143-149, mai./ago., 2014

CAMARENA, P. Didáctica de la matemática en contexto. Educação Matemática Pesquisa, v. 19, n. 2, p. 0126, 2017. DOI: http://dx.doi.org/10.23925/1983-3156.2017v19i2p1-26.

CAMARENA, P. Formación por competencias en las ciencias básicas de la ingeniería. Revista Brasileira de Ensino de Ciência e Tecnologia. Vol. 11, Núm. 2, p.294-320, mai./ago., 2018.

GRAHAM, R. The global state of the art in engineering education. Cambrige: Massachusetts Institute of Technology, 2018.

GOMES, E. et al. Análise Dinâmica de Pórticos: uma oportunidade para a construção de um evento contextualizado para o ensino e a aprendizagem de Álgebra Linear. Em: XLVI Congresso Brasileiro de Educação em Engenharia - Associação Brasileira de Educação em Engenharia, 2018, Anais... Salvador/Brasil, p. 01-10, 2018a.

GOMES, E. et al. Utilização de eventos contextualizados nas aulas de Vetores e Geometria Analítica - primeiras reflexões. Em: XLVI Congresso Brasileiro de Educação em Engenharia - Associação Brasileira de Educação em Engenharia, 2018, Anais... Salvador/Brasil, p. 01-10, 2018 b.

GOMES, E. et al. Evento Contextualizado: estudo de um problema da Engenharia Civil para o ensino de Matemática. Em: XV Conferencia Interamericana de Educación Matemática - Comité Interamericano de Educación Matemática, 2018, Anais... Medellín/Colômbia, p. 01-8, 2019.

LIMA, G. L.; BIANCHINI, B. L.; GOMES, E. Dipcing: uma metodologia para o planejamento ou redirecionamento de programas de ensino de Matemática em cursos de Engenharia. Em: XLIV Congresso Brasileiro de Educação em Engenharia - Associação Brasileira de Educação em Engenharia, 2016, Anais... Natal/BR, p.1-10, 2016.

LIMA, G. L.; BIANCHINI, B. L.; GOMES, E. Conhecimentos docentes e o Modelo Didático da Matemática em Contexto: reflexões iniciais. Educação Matemática Debate, Montes Claros, v.2, n.4, jan./abr. p. 116135, 2018. DOI: http://dx.doi.org/10.24116/emd25266136v2n42018a06

LIMA, G. L.; BIANCHINI, B. L.; GOMES, E. Elaboração de eventos contextualizados para aulas de Cálculo Diferencial e Integral em diferentes cursos de graduação. Acta Latinoamericana de Matemática Educativa, v. 32, n.2, p. 186-194, 2019a.

LIMA, G. L.; BIANCHINI, B. L.; GOMES, E. Comparação entre a Teoria das Situações Didáticas de Brousseau e a Matemática no Contexto das Ciências de Camarena. Educação Matemática Pesquisa, v.21, n.5, p. 132-142, 2019b. DOI: http://dx.doi.org/10.23925/1983-3156.2019v21i5p132-142

LIMA, G. L. et al. O Modelo Didático da Matemática em Contexto como possibilidade para um ensino de Matemática consonante às novas Diretrizes Curriculares Nacionais. Em: XLVII Congresso Brasileiro de Educação em Engenharia - Associação Brasileira de Educação em Engenharia, 2019, Anais... Fortaleza/BR, p.1-09, 2019. 
MARCONI, E. M. A.; LAKATOS, E. V. Fundamentos da metodologia científica. São Paulo: Atlas, 2003. UNIVERSIDADE CORNELL; INSEAD; OMPI. Índice Global de Inovação de 2018: Energizando o Mundo com Inovação, Ithaca, Fontainebleau e Genebra, 2018.

UNIVERSIDADE CORNELL; INSEAD; OMPI. Índice Global de Inovação de 2019: Criar Vidas Sadias - O Futuro da Inovação Médica, Ithaca, Fontainebleau e Genebra, 2019.

\section{Correspondência}

Gabriel Loureiro de Lima: Licenciado, bacharel e mestre em Matemática pela Universidade Estadual de Campinas. Doutor em Educação Matemática pela Pontifícia Universidade Católica de São Paulo. Professor do Programa de Estudos Pós-Graduados em Educação Matemática da PUC-SP.

E-mail: gllima@pucsp.br

Barbara Lutaif Bianchini: Licenciada e bacharel em Matemática pela Pontifícia Universidade Católica de São Paulo. Licenciada em Pedagogia pela Universidade de Franca. Mestre em Educação Matemática pela Pontifícia Universidade Católica de São Paulo e Doutora em Educação (Psicologia da Educação) pela Pontifícia Universidade Católica de São Paulo. Professora do Programa de Estudos Pós-Graduados em Educação Matemática da PUC-SP.

E-mail: barbara@pucsp.br

Eloiza Gomes: Licenciada em bacharel em Matemática pela Universidade Presbiteriana Mackenzie. Mestre e doutora em Educação Matemática pela Pontifícia Universidade Católica de São Paulo. Professora do Instituto Mauá de Tecnologia.

E-mail: eloiza@maua.br

Juliana Martins Philot: Bacharel e mestre em Matemática pela Universidade Estadual Paulista Júlio de Mesquita Filho e doutoranda em Educação Matemática pela Pontifícia Universidade Católica de São Paulo. Professora do Instituto Mauá de Tecnologia.

E-mail: juliana.philot@maua.br

Texto publicado em Currículo sem Fronteiras com autorização dos autores. 